Selling Innovative Products in the Presence of Externalities Yufei Huang

School of Management, University of Bath

Claverton Down, Bath, BA2 7AY, UK

Tel: +44 (0) 122538 4456; Email: y.huang@bath.ac.uk

Bilal Gokpinar

(corresponding author)

UCL School of Management, University College London

1 Canada Square, London, E14 5AB, UK

Tel: +44 (0) 203108 6029; Email: b.gokpinar@ucl.ac.uk

Christopher S. Tang

UCLA Anderson School of Management, University of California

Los Angeles, 110 Westwood Plaza, Los Angeles, CA, 90095

Tel: +1 (310) 825 4203; Email: chris.tang@anderson.ucla.edu

Onesun Steve Yoo

UCL School of Management, University College London

1 Canada Square, London, E14 5AB, UK

Tel: +44 (0) 203108 1038; Email: o.yoo@ucl.ac.uk 


\title{
Selling Innovative Products in the Presence of Externalities
}

\author{
Yufei Huang \\ School of Management, University of Bath, Claverton Down, Bath, BA2 7AY, UK \\ y.huang@bath.ac.uk \\ Bilal Gokpinar \\ UCL School of Management, University College London, 1 Canada Square, London, E14 5AB, UK \\ b.gokpinar@ucl.ac.uk
}

Christopher S. Tang

UCLA Anderson School of Management, University of California, Los Angeles, 110 Westwood Plaza, Los Angeles, CA, 90095 chris.tang@anderson.ucla.edu

Onesun Steve Yoo

UCL School of Management, University College London, 1 Canada Square, London, E14 5AB, UK

o.yoo@ucl.ac.uk

When deciding whether to adopt an innovative product or service, consumers often experience different levels of anxiety (i.e., nervousness) that prompt them to resist purchase (e.g., fear of learning new technologies, disruption of established habits or beliefs). In such cases, consumers' anxiety is mitigated by "validation" through externality (e.g., the number of early adopters). To reduce consumers' anxiety, firms can also invest in "familiarization" through promotion (e.g., offering free trials). We conceptualize innovation as a product that engenders anxiety, and present a model that employs a consumer utility model focusing on the psychological dimension. We examine the firm's profit-maximizing promotion and pricing decisions when selling to forward-looking consumers in the presence of externality. Our equilibrium analysis reveals that, unlike the conventional wisdom for promoting new products, for anxiety-inducing innovations with externality, accelerating the speed of adoption through promotion can actually be detrimental to the firm.

Key words: New product introduction; innovation adoption; consumer anxiety; familiarization; externality History: Received: April 2016; accepted: February 2018 by Stelios Kavadias after three revisions. 


\section{Introduction}

When making a purchasing decision, consumers evaluate both the functional and the psychological benefits and costs of the product (Hellofs and Jacobson 1999) 1 1 For purchase decisions involving new innovative products, psychological factors play a prominent role (Castano et al. 2008). This is because purchasing an innovative product disrupts established habits (Ram 1989, Ram and Sheth 1989), requires learning the necessary steps to use the innovation effectively, or parting from an emotionally attached old technology (Fournier 1998, Hoeffler 2003, Castano et al. 2008). All of these can increase a consumer's anxiety, a nervous feeling regarding the innovative product that can cause her to postpone purchasing decision. While consumers with low anxiety level will likely become early adopters, those with higher anxiety levels may delay their purchase until their anxiety level decreases (Ram and Sheth 1989). Consider the following examples:

- Satellite TV or TV-set top boxes such as Apple TV or ROKU. These innovative products allow consumers to watch TV and stream various programs using a single source at a lower cost than other alternatives including cable TV.

- Contactless payment technology that was recently introduced by Transport for London. This innovative service allows customers to tap their debit/credit cards at the turnstile gates and therefore eliminates the need to wait in line to purchase traditional tickets or travel cards (e.g., an Oyster card).

- Uber or Lyft. These mobile app services allow consumers to access Taxi service within minutes via a smart phone from arbitrary locations at a reduced cost.

Despite the seemingly superior functional benefits that these new-generation products or services offer over existing alternatives, many consumers are still reluctant to adopt them due to various anxieties including: "Will it work with my other products?", "Is it secure enough?", and "Will I be able to use it easily?"

Consumer anxiety can hinder the adoption speed of innovations, and it is one of the determining factors for the success/failure of new product launches (Sheth 1981, Gatignon and Robertson 1989, Ram and Sheth 1989, Castano et al. 2008, Kleijnen et al. 2009). Thus, a firm launching a

\footnotetext{
${ }^{1}$ The psychological component of utility is different from models of bounded rationality, which consider consumers with cognitive limitations or psychological biases. We do not assume consumers use simple heuristics to make complex decisions, or display certain intrinsic psychological tendencies (Ren and Huang 2018).
} 
novel product must manage consumer anxiety to improve adoption speed and maximize profit. In studying how a new innovation spreads in a market, the diffusion literature points to two sets of factors which are (i) internal to consumer population such as their validation through externality, and (ii) external to consumer population, such as firms' promotion and pricing decisions Bass 1969, Gatignon and Robertson 1985, Chatterjee and Eliashberg 1990, Peres et al. 2010).

This observation motivated us to develop a model that captures both the internal factor (i.e., validation through externality) and the external factor (i.e., familiarization through promotion) in this paper. Specifically, consumers reduce their anxiety levels by observing other adopters. For example, an anxious consumer who is initially reluctant to use Uber (or contactless payment or TV top boxes) may become more comfortable adopting it after observing many other users. On the other hand, to reduce consumers' anxiety levels, a firm can actively help consumers familiarize with the innovative products/services by offering free trials or training videos/seminars, allowing easy access to products via showrooms and experience centers Goering 1985, Heiman and Muller 1996), or presenting reassuring messages through general advertising. Naturally, consumers with higher anxiety levels may, in anticipation of their anxiety subsiding in the future, choose to delay their purchase.

In this paper, we conceptualize innovation as a product whose functional benefit is known but its adoption engenders anxiety, and examine firm's appropriate promotion and pricing decisions. We employ a consumer utility model that focuses on psychological anxiety and present a stylized model that captures three salient features: (i) consumers are heterogeneous in their anxiety levels, (ii) psychological anxiety can be reduced by firm's promotion strategy (due to familiarization effect) as well as the number of adopters (due to externality effect), and (iii) consumers are forward-looking (i.e., they may delay their purchase decisions to lower their anxiety or in anticipation of price drops). The analysis of our unified framework results in closed-form equilibrium expressions, which allow us to determine and compare the optimal firm decisions on promotion and pricing and the resulting demand and profits in the presence or absence of externality. We offer insights not only 
on the firm's separate pricing and promotion strategies, but more interestingly, we present new findings on how the interplay between externality and promotion impacts firm profits.

Regarding the optimal pricing strategy, we find that decreasing the selling price over time (price markdown) is always optimal for the firm when externality is absent. However, in the presence of externality, increasing the selling price over time can be optimal for the firm. Lowering price in the early period increases the number of early adopters, which reduces the remaining consumers' anxiety and raises their valuation of the product. Thus, firms can benefit from the mark-up pricing by capturing the late adopters at a premium price. This is consistent with penetration pricing strategy of networked goods (Dhebar and Oren 1985).

More importantly, with regards to firms' optimal promotion strategy, we find that in the presence of externality, employing familiarization strategy can be, even if it is free to implement, detrimental to the firm's profit. That is, higher speed of consumer adoption can lead to lower profits for the firm. Externality benefits the innovative firm because it allows the firm to reap reward from the premium price charged to a larger group of late adopters. Employing familiarization strategy may offset this benefit because it increases the speed of adoption and decreases the number of late adopters.

Existing literature on new products with externalities have primarily focused on pricing Dhebar and Oren 1985, Xie and Sirbu 1995, Gabszewicz and Garcia 2008) and other issues such as firm survival (Srinivasan et al. 2004, Wang et al. 2010), product strategy (Sun et al. 2004), and product upgrade (Padmanabhan et al. 1997). In this study, moving beyond pricing as a profit lever associated with new product introduction, we identify product promotion (familiarization) as a second important lever for innovating firms and address how firms' promotion strategy affect their profits in the presence of externalities.

The rest of the paper is organized as follows. 2 examines our externality mechanism by classifying its type (§2.1) and clarifying its difference to social learning (§2.2). In $\S 3$, we present our stylized model of consumer adoption over two periods. In $\$ 4$, we analyze the impact of firm's familiarization strategy and externality on the consumer adoption and the firm's optimal pricing and profit. We conclude in $\$ 5$. All proofs are provided in the Appendix. 


\section{Externality}

Externality is a key element of our model. However, there are many different types of externality and it sometimes appears to relate to the concept of social learning. In this section, we distinguish our externality mechanism by classifying its type $(\S 2.1)$ and clarifying how it is different from social learning $(\S 2.2)$.

\subsection{Types of Externality}

Consumption externality describes the property that a consumer's utility associated with the consumption of a good (or service) increases with the number of other agents consuming the good. This concept has been formalized from study of networked goods such as the telephone network (Katz and Shapiro 1985), in which the value of consuming a networked product increases when more users are in the network. Such externality can also manifest itself indirectly through complementary products. For example, in the setting of computers, the value of a PC (as opposed to Mac) increases when more consumers use PCs because there will be more software developed for PCs.

This standard concept of externality has since evolved from the traditional network setting into different subgenres of literature based on different contexts. Specifically, externalities can be classified by a two-by-two matrix (Table 1) depending on whether (i) externality influences the functional or psychological component of the utility, and (ii) whether there is positive or negative consumption externality.

\begin{tabular}{|l|l|l|}
\hline & Functional utility & Psychological utility \\
\hline \multirow{3}{*}{ Positive externality } & Networked goods (telephone) or & New technology products, innova- \\
& complementary products (soft- & tions, restaurants, movies, fashion \\
& ware/hardware) & (conformity seeking behavior) \\
\hline Negative externality & Services (utilities, roads) due to & Luxury products (exclusivity seeking \\
& congestion & behavior) \\
\hline
\end{tabular}

Table 1 Four types (2x2) of externality. Our externality mechanism corresponds to the upper right quadrant. 
First, "positive externality" exists for many networked goods. However, it is also present for many non-networked products or services when an increase in the number of adopters increases the consumers' psychological utility by appealing to their penchant for conformity (top half of Table 1). Becker (1991) suggests that the pleasure from a good (e.g., food from a restaurant) may be inherently greater when more people want to consume it. Greater number of early adopters can influence the confidence about a product (Hellofs and Jacobson 1999), creating a perception as a standard (Brynjolfsson and Kemerer 1996), indicating fashion trends which is important for customer subgroups who seek conformity from peers (Abrahamson and Rosenkopf 1993, Moretti 2011), or increasing reputation (Gabszewicz and Garcia 2008).

Second, "negative externality" occurs when a consumer's utility decreases with the number of other users (bottom half of Table 1). For example, in service operations, an increase in the number of customers creates congestion, which decreases the functional benefit of the service (e.g., increased waiting time, more frequent blackouts in utility). Moreover, negative consumption externality can also occur in the psychological domain. For example, in the case of luxury markets, consumers seek exclusivity or status when purchasing the luxury item. As such, the utility derived from purchase decreases as the number of purchasers increases (Gao et al. 2016).

Our setting pertains to positive externality in the psychological domain (upper right quadrant of Table 1). We consider the setting of innovative non-networked product, where a consumer's anxiety subsides when many others adopt the product or services. Despite its wide presence of positive externality of general non-networked goods, its complex effects have received limited attention in the literature (Tellis 2010). We contribute to this growing literature.

\subsection{Externality vs. Social Learning}

A mechanism that often appears simultaneously but is different from externality is "social learning." The two framework are intertwined because both mechanisms are relevant to settings where product qualities are unknown. In this section, we clarify the difference between our externality framework and social learning framework. 
For social learning mechanism, consumers gather (or infer) information from their peers who have already consumed the good (e.g. via customer reviews or word-of-mouth) to update their beliefs. As such, whether the consumer reviews are positive or negative, and how diverse they are, have important implications on consumers' subsequent purchase decisions. In other words, social learning model assumes that individuals care about others' actions only because they convey information about the quality of a product (Banerjee 1992, Bikhchandani et al. 1998). Social learning is therefore appropriate and primarily used for examining consumer purchase decisions based on the functional benefit of the products.

In contrast, externality does not involve updating beliefs and information is not gathered (or inferred). Instead, a consumer's utility from a product depends directly on the observed number of early adopters. In other words, in externality models, the others' actions are relevant because they show the number of adopters.

Despite their stark differences, the impact of social learning and externality have often been difficult to separate both empirically (Moretti 2011) and theoretically (Peres et al. 2010). For example, Moretti (2011) states that many of his conclusions about the impact of social learning on movie sales can also be explained by externality. In the innovation diffusion literature (i.e., Bass (1969) and its extensions), the impacts of interpersonal learning and externality are collapsed as a single parameter (Goldenberg et al. 2010). In organizational theory, social learning and externality are two competing theories that explain diffusion of innovation (Abrahamson and Rosenkopf 1993).

However, the externality and social learning effects are theoretically separable in the extreme cases when: (i) only social learning exist - the quality of a product is unknown and there are no externality effects, or (ii) only externality exist - the quality of a product is perfectly known to customers in advance, and consumers can observe the number of adopters. There have been many recent studies in the operations management and marketing disciplines investigating the former setting - impact of social learning free from externality. These studies conceptualize innovations as products whose quality is unknown to consumers and focus on customers' social learning, e.g., 
via posted reviews by early adopters (Yu et al. 2015, Papanastasiou and Savva 2016). Instead, we study the latter setting — impact of externality without the traditional social learning, which has received limited attention in the literature. (The combination of externality and social learning is beyond the scope of this paper and we defer it as future research.)

In summary, our contribution to the literature is twofold. First, we formalize an alternative conceptualization of an innovation as a product whose functional benefit is known and yet consumers have psychological anxiety about adopting it. A consumer's anxiety is reduced as more consumers purchase the product due to the externality effect (top right quadrant of Table 1). Second, using the unified framework, we examine the firm's optimal promotion and pricing strategy and how it interacts with externality. Our equilibrium analysis reveals that, unlike the conventional wisdom for promoting new products, for anxiety-inducing innovations with externality, accelerating the speed of adoption through familiarization can be detrimental to the firm.

\section{The Model}

A firm introduces a new innovative product to the market with an functional benefit $v$ that is known and common to all consumers (as discussed in $\S ₫ 1$ 2). We focus on this setting with the intention to isolate the effect of externality from (social) learning (Moretti 2011). We consider a two-period model in which the firm seeks to maximize its profit over two periods by making the following decisions. In period 1 (the launch period), the firm determines whether to launch a promotion campaign to familiarize the consumers with the product, then sets the selling price $p_{1}$. In period 2 (post-launch period), after observing the realized demand in period $1, D_{1}$, the firm sets a price $p_{2}$. For ease of exposition, we scale the firm's discount factor to 1 and production cost to 0 .

In our model, all consumers are rational and determine the timing of their purchase to maximize their expected utility. Each consumer has unit demand and consumes the product at the time of purchase. All consumers have a common discount factor $\delta<1$ due to delayed consumption, and a lower (higher) discount factor implies a more myopic (forward-looking) consumer base. (Fully myopic consumer base is a special case of our model with $\delta=0$ ). 
A consumer's expected utility is governed by both functional and psychological components. The functional component consists of the value of the product $v$ (constant over two periods) and prices $p_{1}$ and $p_{2}$. The psychological component pertains to consumers' psychological anxiety about adopting the innovation, which is represented as a psychological disutility. Consumers are heterogeneous in their anxiety levels due to their different prior experiences or knowledge $\left(\begin{array}{ll|l|l|}\text { Hoeffler } & 2003 \text {, Wang }\end{array}\right.$ 1997). We denote consumer $i$ 's initial level of anxiety level as $x_{i}$. For simplicity, we assume that the market comprises of a continuum of consumers with initial anxiety levels $x_{i}$ uniformly distributed over $[0, v]$, and we normalize the market size to 1 (i.e., demand is equivalent to proportion of consumers) $\stackrel{2}{2}^{2}$

Consumer $i$ 's anxiety level in period 1 and 2 depends on his or her initial anxiety level $x_{i}$ and the two effects of familiarization (F) and externality (E). These two effects are respectively external and internal to consumers, consistent with those that govern the speed of adoption in the diffusion literature (Peres et al. 2010). Familiarization (F) happens when the firm invests in a promotion campaign to alleviate consumers' anxiety of adoption such as offering free trials, presenting demonstrations, or general advertising. In our model, the firm can invest $K$ at the beginning of period 1 so that the anxiety levels are reduced by a factor $\alpha<1$ for all consumers (from $x_{i}$ to $\alpha \cdot x_{i}$ ) in periods 1 and 2 . No investment corresponds to $K=0$ and $\alpha=1 !^{3}$ We will refer to the parameter $\alpha$ as the effectiveness of the firm's familiarization effort.

Externality (E) occurs because consumers' period 2 anxiety levels would decrease in the number of early adopters in period $1, D_{1} \biguplus^{4}$ In our model, in the presence of externality, a consumer $i$ 's anxiety level in period $1, x_{i}$ will be revised to $\left(\beta / D_{1}\right) \cdot x_{i}$ in period 2 , where the parameter $\beta \in(0,1)$ is a reference point that helps gauge whether the demand $D_{1}$ is high or low. If the number of ${ }^{2}$ Our model is easily generalizable to the case where the $x_{i}$ is uniformly distributed over $[0, R]$ for any $R$.

${ }^{3}$ We treat $K$ and $\alpha$ as parameters for ease of analysis, but $\alpha$ can be a function of $K$ in principle.

${ }^{4}$ Although early adopters in period 1 can also be influenced by externality (e.g., Dhebar and Oren 1985), we assume that only the late adopters in period 2 benefit from externality because it is more representative of our new product launch setting and also consistent with many other modeling convention (e.g., Bensaid and Lesne 1996). 
adopters in period 1 is above this reference point $\left(D_{1}>\beta\right)$, the number of adopters is deemed large by the consumers and the anxiety level $\left(\beta / D_{1}\right) \cdot x_{i}$ is adjusted downward. On the other hand, if $D_{1}$ is below this reference point $\left(D_{1}<\beta\right)$, demand is considered low by consumers and the anxiety levels for the remaining consumers is increased. This simple adjustment rule follows the convention of modeling externality in the diffusion literature (Goldenberg et al. 2010); it is also a special case of Becker (1991), where a person's demand for a good is positively related to the demand of others, and captures the notion of positive externality that consumers are more (less) willing to enter a restaurant when it is full (empty).

Externality is internal to consumer population and firms have limited control. The reference point $\beta$ is associated with the characteristics of the product market environment Oliver 1980 , Thaler 1985, Hoch and Loewenstein 1991). For example, for certain fashion or high-tech products targeted towards young consumers, relatively small number of early adopters could create a favorable externality effect, corresponding to the case with relatively low reference point $\beta$. However, for some new products such as novel financial investment offerings or new drugs, it may be difficult to achieve a favorable externality effect unless a relatively large number of early adopters have bought into the product. In such case, consumer reference point $\beta$ would be relatively high.

When both familiarization and externality are present $(\mathrm{F}+\mathrm{E})$, consumer $i$ 's anxiety level is reduced from $x_{i}$ to $\alpha x_{i}$ in period 1 , and in period 2 it is further revised to $\alpha\left(\beta / D_{1}\right) x_{i}$. Table 2 summarizes the consumer $i$ 's utilities for the new product in period 1 and period 2 without and with the presence of externality. (Note that $\alpha=1$ represents the firm not investing in familiarization.)

\begin{tabular}{ccc}
\hline & Period 1 & Period 2 \\
\hline F only: & $u_{i}=v-\alpha x_{i}-p_{1}$ & $u_{i}=\delta\left(v-\alpha \cdot x_{i}-p_{2}\right)$ \\
E only: & $u_{i}=v-x_{i}-p_{1}$ & $u_{i}=\delta\left(v-\frac{\beta}{D_{1}} \cdot x_{i}-p_{2}\right)$ \\
F+E: & $u_{i}=v-\alpha x_{i}-p_{1}$ & $u_{i}=\delta\left(v-\frac{\alpha \beta}{D_{1}} \cdot x_{i}-p_{2}\right)$ \\
\hline
\end{tabular}

Table 2 Consumer $i$ 's utilities based on initial anxiety level $x_{i}$, presence of $\mathbf{F}$ or $\mathbf{E}$, and prices $p_{1}, p_{2}$. 
Figure 1 summarizes the sequence of our model. In the beginning of period 1, the firm first determines whether to invest $K$ in promotion campaign ( $K=0$ with no investment) to familiarize consumers and lower their anxiety by a factor $\alpha \leq 1$ (with equality when no investment). It then sets price $p_{1}$. The consumers decide whether to purchase in period 1 or not by comparing their corresponding expected utilities between purchasing now, later, or leaving the market, i.e., $v-\alpha x_{i}-$ $p_{1} \geq \max \left\{\delta\left(v-\alpha\left(\beta / D_{1}\right) x_{i}-p_{2}\right), 0\right\}$. Because both future price $p_{2}$ and anxiety level $\alpha\left(\beta / D_{1}\right) x_{i}$ are not known at the time of decision in period 1, consumers form rational expectations about those values to evaluate their utilities. At the end of period 1 , demand $D_{1}$ is realized, which is observed by the firm and the remaining consumers. In period 2 , the firm sets price $p_{2}$ and the remaining consumers decide to purchase the product based on their revised anxiety levels.

\section{Figure 1 Sequence of events}

Firm's decisions:

- Invest in $\mathrm{F}$ and incur $K$ ?

- Set $p_{1}$

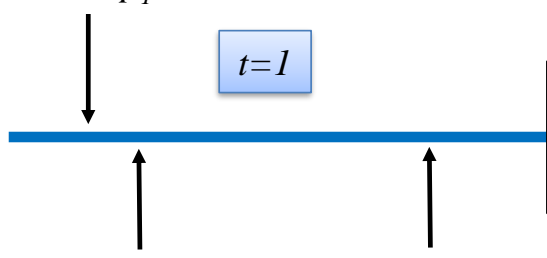

Consumer $i$ 's anxiety level equals: $\alpha x_{i}$ (under F).
Consumer $i$ purchases if $\alpha x_{i}<\tau_{l}$ (under F).

\section{Firm's decision:}

- $\quad$ Set $p_{2}$

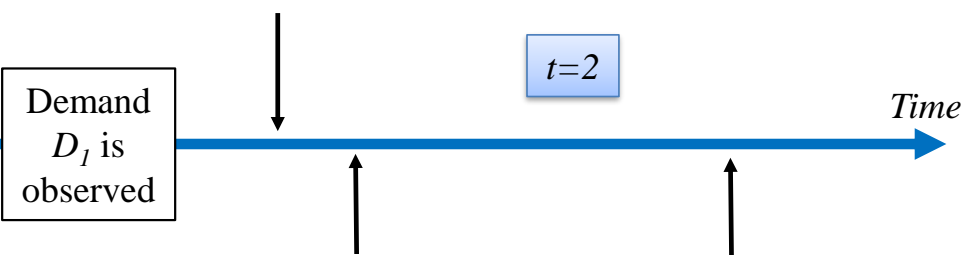

Consumer i's "adjusted" anxiety level equals: $\alpha x_{i}$ (under F), $\beta / D_{1} \cdot x_{i}$ (under $\mathrm{E}$ ), or $\alpha \cdot \beta / D_{1} \cdot x_{i}$ (under F+E).
Consumer $i$ purchases if "adjusted" anxiety level $<\tau_{2}$ (under F, E, or $\mathrm{F}+\mathrm{E}$ ).

Note that consumers with lower anxiety level (below a threshold $\tau_{1}$ ) will adopt the new product early (in period 1), while consumers with higher anxiety level will delay their decision (until period 2) and purchase in period 2 if their anxiety level is below a threshold, $\tau_{2}$. Such purchasing strategy employed by consumers is consistent with Ram and Sheth (1989). The adoption rate is characterized by the thresholds $\tau_{1}$ and $\tau_{2}$. Also, the delay in the purchase decision is driven not only from the anticipation of a lower price, but also from the anticipation of a lower anxiety level, which depends on both firm's pricing decision and consumers' rational expectation. In the rational expectation 
equilibrium, all consumer $i$ 's period 1 expectations about $p_{2}$ and $D_{1}$ coincide with the realized $p_{2}$ and $D_{1}$.

Our model captures the intricate dynamics between the firm and the consumers, and consumers with each other, concerning pricing, familiarization, and externality. Despite its complexity, we will show in the next section that the firm's optimal prices and profit are determined in closed form using backward induction under the rational expectation equilibrium.

\section{Analysis}

To examine the implications of familiarization, externality, and their interaction on the equilibrium outcomes, we first examine independently the setting with familiarization (F) only (4.1) and externality (E) only (4.2). Then, we examine the equilibrium outcomes when both mechanisms $(\mathrm{F}+\mathrm{E})$ are present $(4.3)$, and examine the managerial implication of their interaction 4.4 .

\subsection{Firm's Familiarization Effort ( $F$ only)}

We begin by examining the case where the firm invests $K$ to promote familiarization of the new product to consumers at the time of launch in period 1 . Due to the familiarization effect induced by the promotion, a consumer $i$ 's anxiety level is reduced from $x_{i}$ to $\alpha x_{i}$ throughout periods 1 and 2 , where $\alpha<1$.

Our analysis requires understanding the complex dynamics between the firm and consumers, and consumers forming expectation about the firm's pricing decisions. To build intuition of our equilibrium analysis based on backward induction, consider the case when $\alpha=1$. We begin by analyzing consumers' purchasing decision in period 2. Note that consumers with a lower anxiety level $x_{i} \in\left[0, \tau_{1}\right]$ will have purchased the new product in period 1 in equilibrium (we shall determine the equilibrium threshold $\tau_{1}$ later). Because $x_{i}$ is uniformly distributed over $[0, v]$, the demand in period 1 is $D_{1}=\tau_{1} / v$. Therefore, all remaining consumers in period 2 have an anxiety level $x_{i} \in\left(\tau_{1}, v\right]$. For any given selling price $p_{2}$, a consumer remaining in period 2 will purchase the new product if and only if the consumer's utility $u_{i}=v-x_{i}-p_{2}>0$, i.e., when the anxiety level $x_{i} \leq \tau_{2} \equiv v-p_{2}$. In this case, the demand in period 2 is $D_{2}=\left(\tau_{2}-\tau_{1}\right) / v=\left(v-p_{2}-\tau_{1}\right) / v$. 
Anticipating the demand $D_{2}$ in period 2 as given above, the firm sets price $p_{2}$ to maximize its period 2 profit $\left(\pi_{2}\right)$,

$$
\pi_{2}^{*}=\max _{p_{2}} p_{2} \cdot D_{2}\left(p_{2}\right)=\max _{p_{2}} p_{2} \cdot \frac{v-p_{2}-\tau_{1}}{v} .
$$

Taking the first-order condition with respect to $p_{2}$, we obtain the following optimal price, demand, and profit in period 2 as a function of $\tau_{1}$ :

$$
p_{2}^{*}\left(\tau_{1}\right)=\frac{v-\tau_{1}}{2} ; \quad D_{2}^{*}\left(\tau_{1}\right)=\frac{v-\tau_{1}}{2} \frac{1}{v} ; \quad \pi_{2}^{*}\left(\tau_{1}\right)=\left(\frac{v-\tau_{1}}{2}\right)^{2} \frac{1}{v} .
$$

We next examine the period 1 problem where the firm selects $p_{1}$ to maximize its total profit in both periods. First, observe that in a rational expectation equilibrium, a consumer will purchase the new product in period 1 if and only if her surplus from purchasing in period 1 is non-negative and is higher than the surplus from purchasing in period 2, i.e., $v-x_{i}-p_{1} \geq 0$ and $v-x_{i}-p_{1} \geq$ $\delta\left(v-x_{i}-p_{2}\right)$. Hence, in equilibrium, a consumer with anxiety level $x_{i}=\tau_{1}$ is indifferent between purchasing in period 1 or period 2 , so that $v-\tau_{1}-p_{1}=\delta\left(v-\tau_{1}-p_{2}\right)$. By using the fact that $p_{2}^{*}\left(\tau_{1}\right)=\frac{v-\tau_{1}}{2}$, the equilibrium price $p_{1}$ can be expressed as a function of $\tau_{1}$,

$$
p_{1}\left(\tau_{1}\right)=\left(1-\frac{\delta}{2}\right)\left(v-\tau_{1}\right)
$$

Second, recall that the demand in period 1 is $D_{1}\left(p_{1}\right)=\tau_{1} / v$. Because the firm's profit in period 2 is given as $\pi_{2}^{*}\left(\tau_{1}\right)=\left(\frac{v-\tau_{1}}{2}\right)^{2} \frac{1}{v}$, the firm's problem for period 1 can be formulated as:

$$
\begin{gathered}
\pi^{*}=\max _{p_{1}} p_{1} \cdot \frac{\tau_{1}}{v}+\pi_{2}^{*}\left(\tau_{1}\right) \\
\text { s.t. 11 holds. }
\end{gathered}
$$

Using (1) to transform the decision variable from $p_{1}$ to $\tau_{1}$, the firm's problem is reformulated to

$$
\pi^{*}=\max _{\tau_{1} \leq v}\left\{\left(1-\frac{\delta}{2}\right) \frac{\left(v-\tau_{1}\right) \tau_{1}}{v}+\left(\frac{v-\tau_{1}}{2}\right)^{2} \frac{1}{v}\right\} .
$$

Because the objective function is concave in $\tau_{1}$, one can use the first-order condition to determine the optimal value of $\tau_{1}$, which can in turn be used to retrieve the equilibrium outcomes for both periods $-p_{1}^{*}, p_{2}^{*}, D_{1}^{*}$, and $D_{2}^{*}$ - in closed form. 
This argument can be extended to the case where $\alpha<1$ by replacing $x_{i}$ with $\alpha x_{i}$. When $\alpha$ is sufficiently small, the analysis must take into account the boundary condition that demand across both periods is limited to $1\left(D_{1}^{*}+D_{2}^{*}=1\right)$, i.e., market saturation occurs (See Appendix for details). We obtain the following results.

Proposition 1 (Familiarization only). When the firm invests $K$ in familiarization effort to alleviate consumer anxiety by a factor of $\alpha$, the equilibrium prices $\left(p_{1}^{*}, p_{2}^{*}\right)$, demands $\left(D_{1}^{*}, D_{2}^{*}\right)$, and total profit $\left(\pi^{*}\right)$ can be expressed as follows: Let $\hat{\alpha}(\delta) \equiv \frac{2+\sqrt{4-(3+\delta) \frac{(2-\delta)^{2}}{(3-2 \delta)}}}{3+\delta}$.

1. When $\alpha \geq \hat{\alpha}(\delta)$,

$$
\begin{array}{rlrl}
p_{1}^{*} & =\frac{v}{2} \frac{(2-\delta)^{2}}{3-2 \delta}, & p_{2}^{*} & =\frac{v}{2} \frac{2-\delta}{3-2 \delta} \\
D_{1}^{*} & =\frac{1}{\alpha} \frac{1-\delta}{3-2 \delta}, & D_{2}^{*}=\frac{1}{2 \alpha} \frac{2-\delta}{3-2 \delta} \\
\pi^{*}=\frac{v}{4 \alpha} \cdot \frac{(2-\delta)^{2}}{3-2 \delta}-K ; &
\end{array}
$$

2. When $\alpha<\hat{\alpha}(\delta)$,

$$
\begin{array}{rlrl}
p_{1}^{*} & =v\left(1-\alpha\left(\frac{1+\delta}{2}\right)\right), & p_{2}^{*}=(1-\alpha) v, \\
D_{1}^{*}=\frac{1}{2}, & D_{2}^{*}=\frac{1}{2}, \\
\pi^{*}=\frac{v}{4}(4-\alpha(3+\delta))-K . &
\end{array}
$$

Proposition 1 thus presents a comprehensive characterization of the equilibrium prices, demands, and profit, as well as their dependence on the effectiveness of familiarization $(\alpha)$ and consumers' forward-looking behavior $(\delta)$. For instance, when familiarization effect is such that the revised anxiety levels $x_{i}$ is reduced moderately $(\alpha \geq \hat{\alpha}(\delta))$, the firm does not capture the whole market (i.e., $\left.D_{1}^{*}+D_{2}^{*}<1\right)$ and the optimal profit $\pi^{*}$ is convex and decreasing in $\alpha$. When the familiarization effect is strong so that the anxiety levels $x_{i}$ is reduced significantly $(\alpha<\hat{\alpha}(\delta))$, the firm saturates the market (i.e., $D_{1}^{*}+D_{2}^{*}=1$ ) and the optimal profit $\pi^{*}$ is linearly decreasing in $\alpha$.

The following corollary examines the structural properties of the equilibrium outcomes under familiarization.

\section{Corollary 1 (Structural Properties of Equilibrium Outcomes (F only)).}

The equilibrium outcomes exhibit the following characteristics. For any effectiveness level $\alpha$, 
(i) the firm will reduce its selling price in period 2, i.e., $p_{1}^{*} \geq p_{2}^{*}$;

(ii) the majority of consumers will purchase in period 2, i.e., $D_{1}^{*} \leq D_{2}^{*}$;

(iii) the firm's profit $\pi^{*}$ is decreasing in the discount factor $\delta, \forall \alpha$.

Corollary 1 can be interpreted as follows. First, because the level of anxiety is reduced by the same factor $\alpha$ in both periods, all remaining consumers in period 2 will have relatively higher anxiety level than the early adopters who purchased in period 1 . To entice them to purchase and generate demand in period 2 , the firm has to reduce its price in period 2 . In turn, a majority of consumers do not purchase in period 1 because they anticipate that price will fall in the second period. Only those with low anxiety levels will purchase in period 1. Finally, as the discount factor $\delta$ increases, more consumers are willing to postpone their purchasing decision until period 2 to purchase at a lower price, resulting in lower profit for the firm.

Figure 2 illustrates the optimal profit $\pi^{*}$ with respect to $\alpha \in[0,1]$ when the promotion requires investment of $K=2$. The firm's optimal profit is continuous and convex decreasing in $\alpha$. The profit without promotion ( $K=0$ and $\alpha=1$ ) is represented by the horizontal dotted line. Figure 2 confirms the intuition that investing in familiarization is beneficial only when, relative to cost $(K)$, the familiarization effect is sufficiently strong ( $\alpha$ sufficiently low). This intuitive result is also consistent with broad marketing literature (Lilien et al. 1992) which highlights the beneficial effects of consumers' familiarization with new products (e.g., offering free samples/trials, advertising) on firms' profits.

It is interesting to observe that familiarization alone, regardless of its effectiveness, fails to significantly influence neither the firm's markdown pricing strategy, i.e., $p_{1}^{*} \geq p_{2}^{*}$, nor the consumer purchase behavior, i.e., $D_{1}^{*} \leq D_{2}^{*}$. That is, regardless of the effectiveness of familiarization $(\alpha)$, a majority of consumers purchase the product at a reduced price in period 2. We will see later (in \$4.3 whether this observation would be altered in the presence of externality.

\subsection{Externality among Consumers (E only)}

We now examine the equilibrium outcomes when only externality (E) is present. Recall that the initial anxiety level $x_{i}$ of all remaining consumer $i$ in period 2 will be adjusted to $\left(\beta / D_{1}\right) \cdot x_{i}$. Thus, 
Figure 2 The optimal firm profit with familiarization with respect to its effectiveness $(\alpha)$.

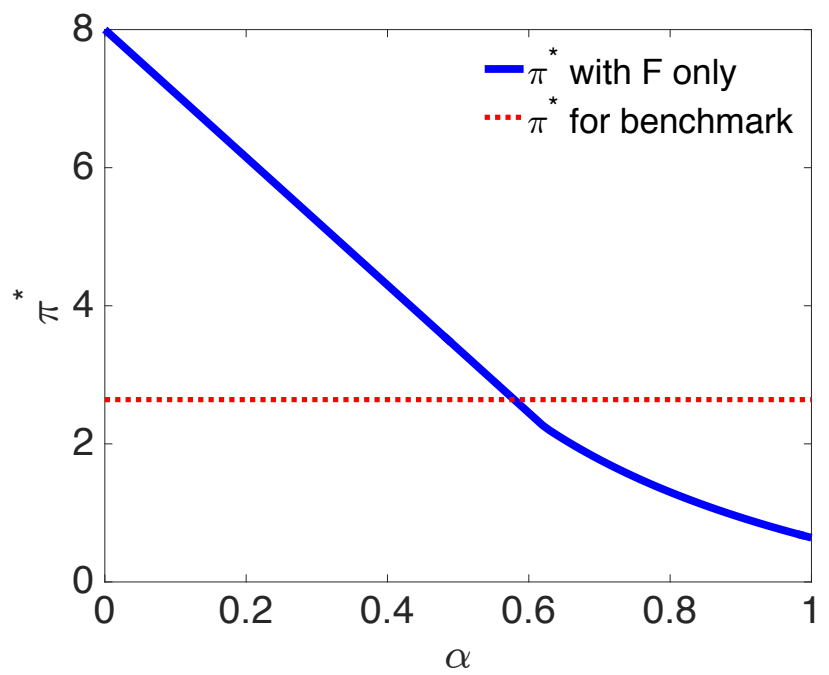

Note. In this plot, $\delta=0.7, \hat{\alpha}(\delta=0.7)=0.6$, and $K=2$.

in the presence of externality, consumers may delay their purchase decisions also in anticipation of observing a large number of early adopters $D_{1}$ and lowering their anxiety levels.

When taking this positive externality into consideration, the firm may want to lower its price in period 1 to generate higher early demand, which will reduce the anxiety for those remaining consumers in period 2. However, selling at reduced price to too many consumers is also not desirable. For consumers, in addition to forming expectation about the firm's pricing decisions, they must also form expectation about other consumers' purchase decisions to make their purchase decision in period 1. Despite the added complexity, similar equilibrium analysis using backward induction outlined in the previous section can be employed (to avoid repetition, see Appendix for details). We next present the closed-form equilibrium that emerges in the presence of externality.

Proposition 2 (Externality only). When consumers adjust their anxiety level from $x_{i}$ to $\left(\beta / D_{1}\right) \cdot x_{i}$ according to externality at the beginning of period 2 , the equilibrium prices $\left(p_{1}^{*}, p_{2}^{*}\right)$, demands $\left(D_{1}^{*}, D_{2}^{*}\right)$, and the total profit for both periods $\left(\pi^{*}\right)$ can be expressed as follows: $\exists \hat{\beta}(\delta)$ available in implicit form such that, 
1. If $\beta<\hat{\beta}(\delta)$, then

$$
\begin{array}{rlrl}
p_{1}^{*} & =v(1+\delta \beta)-\frac{\delta \beta v^{2}}{\tau_{1}^{*}}-\tau_{1}^{*}, & p_{2}^{*}=v-\frac{\beta v^{2}}{\tau_{1}^{*}} \\
D_{1}^{*}=\frac{\tau_{1}^{*}}{v}, & D_{2}^{*}=\frac{v-\tau_{1}^{*}}{v}, \\
\pi^{*}=p_{1}^{*} D_{1}^{*}+p_{2}^{*} D_{2}^{*}, &
\end{array}
$$

where

$$
\begin{aligned}
\tau_{1}^{*}=\max \left\{\frac{v \delta(1+\beta)}{2}, v\right. & \left(\frac{\delta \beta}{6}+\left[\left(\frac{\delta \beta}{6}\right)^{3}+\frac{\beta}{4}+\sqrt{\frac{\beta}{2}\left(\frac{\delta \beta}{6}\right)^{3}+\left(\frac{\beta}{4}\right)^{2}}\right]^{\frac{1}{3}}\right. \\
+ & {\left.\left[\left(\frac{\delta \beta}{6}\right)^{3}+\frac{\beta}{4}-\sqrt{\frac{\beta}{2}\left(\frac{\delta \beta}{6}\right)^{3}+\left(\frac{\beta}{4}\right)^{2}}\right]^{\frac{1}{3}}\right) ; }
\end{aligned}
$$

2. If $\beta \geq \hat{\beta}(\delta)$, then

$$
\begin{array}{rlrl}
p_{1}^{*} & =\frac{v}{2}\left(1-\frac{\delta(1-\beta)}{2}-\frac{(1-\beta)^{2}}{4 \beta}\right), & p_{2}^{*}=\frac{v}{2}(1-\beta), \\
D_{1}^{*}=\frac{1}{2}\left(1-\frac{\delta(1-\beta)}{2}+\frac{(1-\beta)^{2}}{4 \beta}\right), & D_{2}^{*}=\frac{(1-\beta)}{4 \beta}\left(1-\frac{\delta(1-\beta)}{2}+\frac{(1-\beta)^{2}}{4 \beta}\right), \\
\pi^{*}=\frac{v}{4}\left(\frac{1-\delta}{2}+\left(\frac{2 \delta+1}{4}\right) \beta+\frac{1}{4 \beta}\right)^{2} . &
\end{array}
$$

Proposition 2 fully characterizes the equilibrium prices, demands, and profit, and their dependence on consumers' reference point for externality $(\beta)$ and forward-looking behavior $(\delta)$. First, suppose that the consumer reference point $\beta$ is not large $(\beta<\hat{\beta}(\delta))$ so that less number of early adopters can increase the utility of the late adopters. In such case, externality effect is favorable to the firm because the anxiety levels would be more easily adjusted downward by the remaining consumers in period 2, leading to higher demand in period 2. In this case, the firm is able to saturate the market, i.e., $D_{1}^{*}+D_{2}^{*}=1$. Second, suppose that consumer reference point $\beta$ is large $(\beta \geq \hat{\beta}(\delta))$ so that only a large number of early adopters would increase the utility of the late adopters. In such case, the externality effect is unfavorable to the firm because the anxiety levels of the remaining consumers would be less easily adjusted downwards. As a result, the firm does not capture the whole market, and $D_{1}^{*}+D_{2}^{*}<1$.

The following corollary examines the structural properties of the equilibrium outcomes and the impact of externality. 


\section{Corollary 2 (Structural Properties of Equilibrium Outcomes (E only)).}

In the presence of externality where consumers adjust their anxiety level from $x_{i}$ to $\left(\beta / D_{1}\right) \cdot x_{i}$ at the beginning of period 2 ,

(i) the firm employs a markup pricing $\left(p_{1}^{*}<p_{2}^{*}\right)$ when $\beta$ is lower and a markdown pricing $\left(p_{1}^{*} \geq p_{2}^{*}\right)$ when $\beta$ is higher;

(ii) the equilibrium demands are so that $D_{1}^{*}<D_{2}^{*}$ when $\beta$ is lower and $D_{1}^{*} \geq D_{2}^{*}$ when $\beta$ is higher;

(iii) the firm's profit $\pi^{*}$ is decreasing in the discount factor $\delta, \forall \beta$.

When consumer reference level $\beta$ is lower (i.e., when the externality effect is favorable), mark-up pricing is optimal (i.e., $p_{1}^{*}<p_{2}^{*}$ ). A low initial price $p_{1}$ will generate sufficient demand in period 1 (i.e., $D_{1}$ ) that would reduce the anxiety of the remaining consumers in period 2. As a result, consumers in period 2 would have higher utility for the product, and the firm can afford to charge a higher premium price in period 2. Interestingly, a majority of consumers will choose to delay purchase, despite the lower price in period 1, because they anticipate a lower anxiety level in period 2. This result elucidates why favorable externality can significantly benefit firm's profit: it allows the firm to charge a premium price to a majority of consumers in period 2 .

When consumer reference level $\beta$ is higher, however, mark-down pricing is optimal (i.e., $p_{1}^{*}>p_{2}^{*}$ ). To generate a favorable (or at least avoid unfavorable) externality effect, the firm must set a sufficiently low price in period 1 to generate a high enough demand $D_{1}$. The decrease in profit in period 1 however, is not warranted given that there will be less remaining consumers in period 2 to profit from. At the same time, a majority of consumers choose to purchase early in period 1 despite the lower price in period 2. This is because the extent of the mark-down is not significant and they anticipate the anxiety level to not go down significantly and do not want to delay consumption.

Finally, the firm's profit decreases when consumers are forward looking (higher $\delta$ ). As consumers become more forward looking ( $\delta$ increases), they are more prone to wait, thus lowering period 1 demand. In the presence of externality, reduction of period 1 demand also has an unfavorable effect for the firm's period 2 demand. In other words, consumers' forward-looking behavior lowers demand 
(and prices) in both periods 1 and 2 and hurts the firm. It is interesting to observe that unlike effect of familiarization, presence of externality does fundamentally influence the firm's pricing strategy and consumer adoption behavior in equilibrium.

These results with forward-looking consumers are consistent with previous studies which investigate dynamic pricing with externality (Dhebar and Oren 1985, Bensaid and Lesne 1996). The firm may implement mark-down or mark-up pricing depending on the intensity of the externality effect. Namely, if the externality effect is strong enough, the firm adopts mark-up pricing, otherwise, it adopts mark-down pricing (Bensaid and Lesne 1996).

Figure 3 plots the optimal profit in the presence of externality with respect to the consumer reference level $\beta \in(0,1)$. The optimal firm profit $\pi^{*}$ is continuous and convex in $\beta$, but no longer monotonic. The profit with no externality (and no familiarization effort by the firm, $K=0$ and $\alpha=1$ ) is illustrated again by the horizontal dotted line. As discussed, we observe that externality is beneficial when the consumer reference level $\beta$ is lower (favorable), and detrimental when it is higher (unfavorable).

Figure 3 The optimal firm profit in the presence of externality with respect to consumer reference point $\beta$.

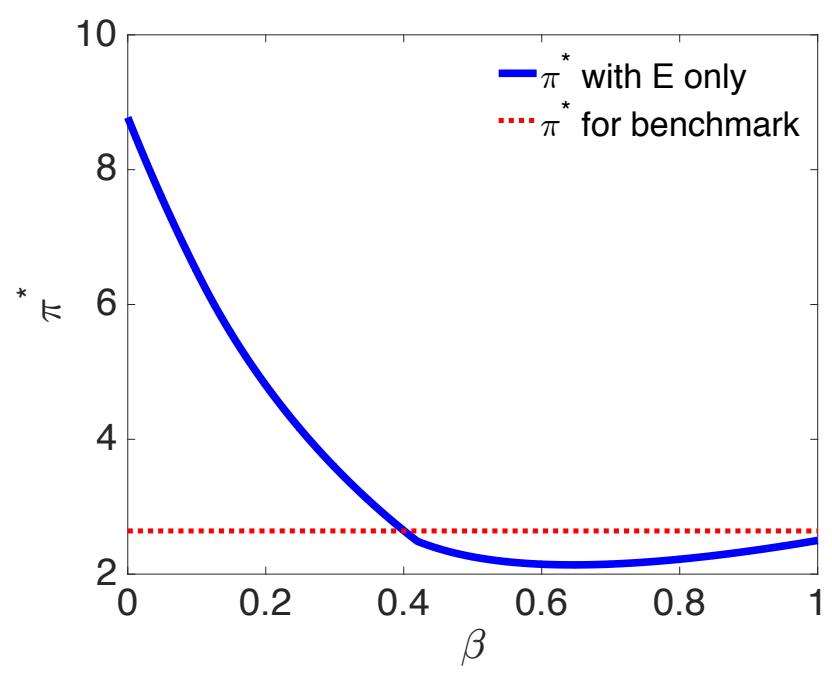

Note. In this plot, $\delta=0.7$ and $\hat{\beta}(\delta=0.7)=0.42$.

Given that an effective familiarization effort (lower $\alpha$ ) or the presence of favorable externality (lower $\beta$ ) each benefits the firm independently, it may appear that employing a familiarization 
campaign in the presence of externality can only benefit the firm. We shall show that this intuition is not necessarily true in the next section.

\subsection{Combined Effect of Familiarization and Externality $(F+E)$}

In this section, we examine the equilibrium outcomes when both anxiety-mitigating mechanisms of familiarization (F) and externality (E) are present. In this setting, recall that the anxiety level of consumer $i$ is reduced from $x_{i}$ to $\alpha x_{i}$ in period 1 due to firm's familiarization effort, and then from $\alpha x_{i}$ to $\alpha\left(\beta / D_{1}\right) \cdot x_{i}$ in period 2 due to externality. Using the same equilibrium analysis of the previous section, we establish the following closed form equilibrium results.

Proposition 3 (Familiarization and Externality). When the firm invests $K$ in familiarization effort and externality is present among consumers, the equilibrium prices $\left(p_{1}^{*}, p_{2}^{*}\right)$, demands $\left(D_{1}^{*}, D_{2}^{*}\right)$ and total profit $\left(\pi^{*}\right)$ can be expressed as follows: $\exists \hat{\beta}(\alpha, \delta)$ available in an implicit form such that,

1. If $\beta \geq \hat{\beta}(\alpha, \delta)$, then

$$
\begin{array}{rlrl}
p_{1}^{*} & =\frac{v}{2}\left(1-\frac{\delta(1-\alpha \beta)}{2}-\frac{(1-\alpha \beta)^{2}}{4 \alpha \beta}\right), & p_{2}^{*}=\frac{v}{2}(1-\alpha \beta), \\
D_{1}^{*}=\frac{1}{2 \alpha}\left(1-\frac{\delta(1-\alpha \beta)}{2}+\frac{(1-\alpha \beta)^{2}}{4 \alpha \beta}\right), & D_{2}^{*}=\frac{1}{4 \alpha} \frac{(1-\alpha \beta)}{\alpha \beta}\left(1-\frac{\delta(1-\alpha \beta)}{2}+\frac{(1-\alpha \beta)^{2}}{4 \alpha \beta}\right), \\
\pi^{*}=\frac{v}{4 \alpha}\left(\frac{1-\delta}{2}+\left(\frac{2 \delta+1}{4}\right) \alpha \beta+\frac{1}{4 \alpha \beta}\right)^{2}-K ; &
\end{array}
$$

2. If $\beta<\hat{\beta}(\alpha, \delta)$, then

(a) If $\alpha \geq \frac{\delta}{2-\delta \beta}$,

$$
\begin{array}{rlrl}
p_{1}^{*} & =v(1+\delta \alpha \beta)-\frac{\delta \alpha \beta v^{2}}{\tau_{1}^{*}}-\alpha \tau_{1}^{*}, & p_{2}^{*}=v-\frac{\alpha \beta v^{2}}{\tau_{1}^{*}}, \\
D_{1}^{*}=\frac{\tau_{1}^{*}}{v}, & D_{2}^{*}=\frac{v-\tau_{1}^{*}}{v}, \\
\pi^{*}=p_{1}^{*} D_{1}^{*}+p_{2}^{*} D_{2}^{*}-K, &
\end{array}
$$

where

$$
\begin{aligned}
\tau_{1}^{*}=\max \left\{\frac{v \delta(1+\alpha \beta)}{2 \alpha},\right. & v\left(\frac{\delta \beta}{6}+\left[\left(\frac{\delta \beta}{6}\right)^{3}+\frac{\beta}{4}+\sqrt{\frac{\beta}{2}\left(\frac{\delta \beta}{6}\right)^{3}+\left(\frac{\beta}{4}\right)^{2}}\right]^{\frac{1}{3}}\right. \\
+ & {\left.\left[\left(\frac{\delta \beta}{6}\right)^{3}+\frac{\beta}{4}-\sqrt{\frac{\beta}{2}\left(\frac{\delta \beta}{6}\right)^{3}+\left(\frac{\beta}{4}\right)^{2}}\right]^{\frac{1}{3}}\right) }
\end{aligned}
$$


(b) If $\alpha<\frac{\delta}{2-\delta \beta}$, then

$$
\begin{array}{ll}
p_{1}^{*}=v\left(1-\frac{\delta(1-\alpha \beta)}{2}-\frac{2 \alpha^{2} \beta}{1+\alpha \beta}\right), & p_{2}^{*}=v\left(1-\frac{2 \alpha^{2} \beta}{\delta(1+\alpha \beta)}\right) \\
D_{1}^{*}=1, & D_{2}^{*}=0, \\
\pi^{*}=v\left(1-\frac{\delta(1-\alpha \beta)}{2}-\frac{2 \alpha^{2} \beta}{1+\alpha \beta}\right)-K . &
\end{array}
$$

Proposition 3 fully characterizes the equilibrium outcomes and their dependence on familiarization effectiveness $(\alpha)$, reference point for externality $(\beta)$, and consumers' forward-looking behavior $(\delta)$. Figure 4 represents the three parts of Proposition 3 in $(\alpha, \beta) \in[0,1] \times[0,1]$ delineated by thresholds $\hat{\beta}(\alpha, \delta)$ (solid curve) and $\frac{\delta}{2-\delta \beta}$ (dotted curve) for $\delta=0.7$ (left panel) and $\delta=0.95$ (right panel). Unlike $\frac{\delta}{2-\delta \beta}$, observe that the implicit threshold $\hat{\beta}(\alpha, \delta)$ is robust to the changes in $\delta$.

Figure 4 Thresholds separating three regions in the $(\alpha, \beta)$ space for $\delta=0.7$ (left panel) and $\delta=0.95$ (right panel).
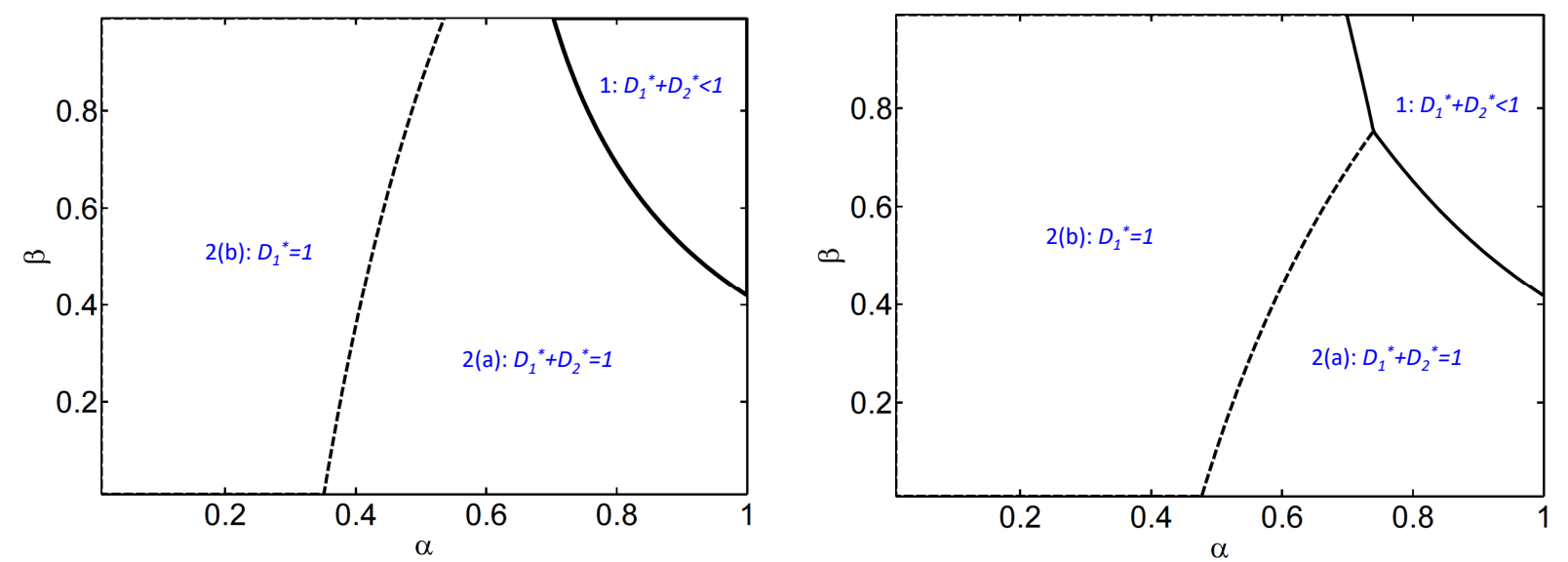

Note. The solid curve represents $\hat{\beta}(\alpha, \delta)$ and the dotted curve represents $\alpha=\frac{\delta}{2-\delta \beta}$.

The first part shows that if firm's familiarization effort has moderate effect (higher $\alpha$ ) and the externality is unfavorable to the firm (higher $\beta$ ), the firm does not saturate the market and $D_{1}^{*}+D_{2}^{*}<1$. Otherwise, the firm captures the whole market (i.e., $D_{1}^{*}+D_{2}^{*}=1$ ), consistent with both Propositions 1 2. Unlike Propositions 12 however, it is possible for the firm to accelerate adoption to saturate the whole market in period 1 (i.e., $D_{1}^{*}=1$ ) and it may be optimal to do so when familiarization is sufficiently effective $(\alpha<\delta /(2-\delta \beta))$. This threshold on $\alpha$ is sensitive to the 
consumers' forward looking behavior $(\delta)$. Recall that consumers' forward-looking behavior hurts the firm's period 2 demand as well as period 1 in the presence of externality. Indeed, as consumers become more forward-looking (high $\delta$ ), the threshold shifts towards the right (left panel vs right panel of Figure 4) and it becomes optimal for the firm to sell out in the first period to block out the unfavorable effect of externality for less effective familiarization level $\alpha$.

The following results reveal the structural properties of equilibrium outcomes and how familiarization and externality interact to influence them.

Corollary 3 (Structural Properties of Equilibrium Outcomes $(\mathbf{F}+\mathbf{E})$ ). Consider the case when the firm invests $K$ to induce the familiarization effect in the presence of externality.

(i) For any $\beta$, as $\alpha$ decreases, $p_{1}^{*}$ decreases and $p_{2}^{*}$ increases, shifting the optimal pricing from mark-down towards mark-up pricing;

(ii) For any $\beta$, as $\alpha$ decreases, demands in both periods $D_{1}^{*}$ and $D_{2}^{*}$ increase in region $1 ; D_{1}^{*}$ increases to 1 and $D_{2}^{*}$ decreases to 0 in region $2(a)$; and remain unchanged at $D_{1}^{*}=1$ and $D_{2}^{*}=0$ in region 2(b);

(iii) The firm's profit $\pi^{*}$ is decreasing in the discount factor $\delta, \forall \alpha, \beta$.

The first part of Corollary 3 shows that, unlike the setting without externality $(4.1)$, the effectiveness of familiarization $(\alpha)$ does influence equilibrium prices. Namely, more effective familiarization campaign decreases the optimal period 1 price $\left(p_{1}^{*}\right)$ and increases the optimal period 2 price $\left(p_{2}^{*}\right)$, thereby reducing the extent of the markdown. Furthermore, depending on the favorability of externality $\beta$, it could fundamentally shift the firm's pricing strategy from mark-down pricing to mark-up pricing.

The second part of Corollary 3 reveals that increasing the effectiveness of familiarization campaign has the effect of shifting demand from period 2 to period 1. As $\alpha$ decreases further, all consumers purchase in period 1 (region 2(b) in Figure 4), at which point a further decrease in $\alpha$ has no effect on the demand. Finally, as expected, consumers' forward looking behavior hurts firm's profit. 
Figure 5 illustrates the firm's optimal profit $\pi^{*}$ with respect to $(\alpha, \beta) \in[0,1] \times[0,1]$ via contour curves for $\delta=0.7$ (left panel) and $\delta=0.95$ (right panel). In both panels, as expected, profit is lowest when familiarization is not effective and externality is unfavorable (high $\alpha$ and $\beta$ ). Surprisingly, profit is not the highest when familiarization is effective and externality is favorable (low $\alpha$ and low $\beta$ ). Instead, we observe two local peaks: (i) when familiarization is effective and externality is unfavorable (low $\alpha$ and high $\beta$ ) and (ii) when familiarization is not effective and externality is favorable (high $\alpha$ and low $\beta$ ).

Figure 5 Optimal profit $\pi^{*}$ represented by contour plots in $(\alpha, \beta) \in[0,1] \times[0,1]$ for $\delta=0.7$ (left panel) and $\delta=0.95$ (right panel).
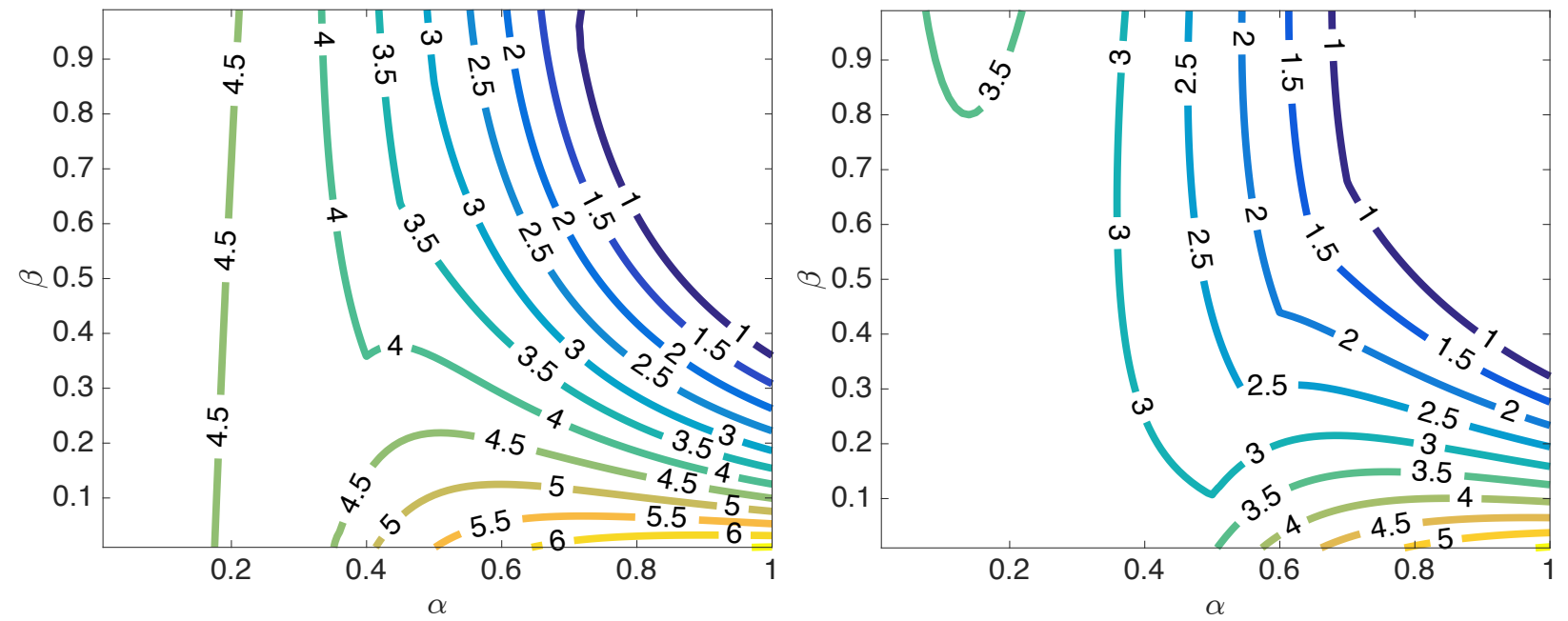

Note. Profit is lowest when familiarization is not effective and externality is unfavorable (high $\alpha$ and $\beta$ ), but profit is not the highest when familiarization is effective and externality is favorable (low $\alpha$ and $\beta$ ). Instead, two local peaks exist when (i) familiarization is not effective and externality is favorable (high $\alpha$ and low $\beta$ ) or (ii) familiarization is effective and externality is unfavorable (low $\alpha$ and high $\beta$ ).

This can be explained as follows. First, when the effect of externality is unfavorable (higher $\beta$ ), more effective familiarization (smaller $\alpha$ ) increases firm profit because it helps ensure that sufficient period 1 demand is generated, thus helping the firm negate the unfavorable effect of externality. On the other hand, when the effect of externality is favorable (lower $\beta$ ), more effective familiarization (smaller $\alpha$ ) decreases firm profit. Recall from Corollary 2 that favorable externality (low $\beta$ ) benefits 
the firm because it enables firms to charge a premium price in period 2 (via markup pricing) to a large majority of consumers. As familiarization becomes more effective, it shifts the demand from period 2 to period 1 (Corollary 3-(ii)), negating the beneficial effect of externality.

Thus far, we have presented insights into how the complex interaction between familiarization and externality influences firm profits. In the next section, we examine the managerial implications.

\subsection{Managerial Implications of Interaction between Familiarization and Externality}

To examine the implication of the interaction between familiarization (F) and externality (E) on the firm's decision to invest in a familiarization campaign, we compare the optimal firm profit with both familiarization and externality $\left(\pi^{*}(F+E)\right)$ to that with externality only $\left(\pi^{*}(E)\right)$. Taking advantage of the closed form expressions of equilibrium profits in Propositions 243 , we are able to examine the values of $(\alpha, \beta)$ and $\delta$ for which $\pi^{*}(F+E)>\pi^{*}(E)$. Figure 6 comprehensively characterizes the region in the $(\alpha, \beta)$ space where additional familiarization in the presence of externality helps or hurts firm profit, for $\delta=0.7$ (left panel) and $\delta=0.95$ (right panel).

Figure 6 Plots of regions where additional familiarization in the presence of externality helps or hurts firm profit $\pi^{*}$ for $\delta=0.7$ (left panel) and $\delta=0.95$ (right panel), for $K=2$.
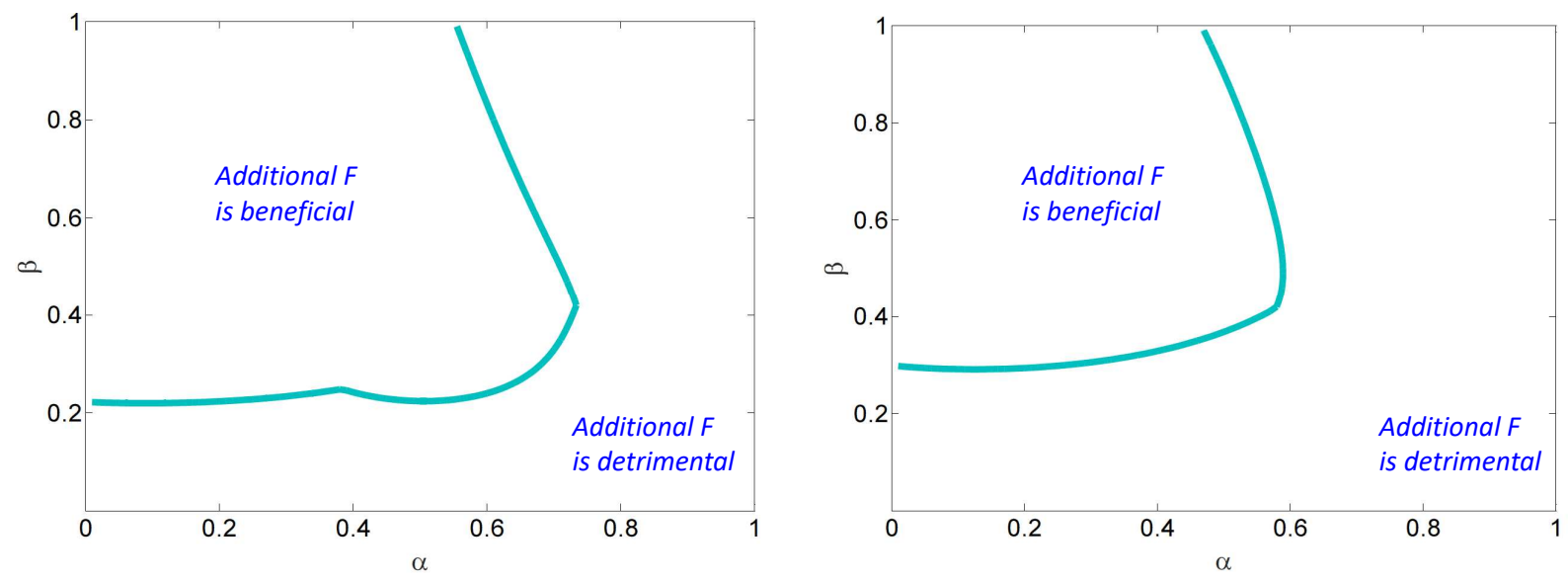

First, we observe in both panels displayed in Figure 6 that additional familiarization campaign is beneficial in the region with unfavorable externality (high consumer reference point $\beta$ ) and effective familiarization (low $\alpha$ ). When $\beta$ is high, running a familiarization campaign that is less effective (high $\alpha$ ) is not recommended because the incremental benefits from increased demand outweighs 
the incremental cost $K$ of running the promotion campaign. This is intuitive, and is also consistent with the result when externality is not present $(\$ 4.1)$, where we showed that familiarization is beneficial only when it is sufficiently effective $(\alpha)$ relative to cost $(K)$.

Interestingly, we find that in the presence of favorable externality (low consumer reference point $\beta$ ), even running a highly effective familiarization campaign is detrimental to the firm. This is true even when familiarization effort is costless, i.e., when $K=0.5$ Why would additional familiarization effort exerted by the firm ever backfire when externality effect is favorable? Recall that externality is favorable to the firm when $\beta$ is lower because it enables the firm to charge a premium price in period 2 to a large number of eager-to-purchase late adopters (Corollary 2). When familiarization is introduced, it accelerates the adoption (shifts demand from period 2 to period 1), and saturates the market too early (i.e., in period 1). As such, accelerated adoption may increase the profit in the short term (period 1), but it is not profitable over the long term (periods 1 and 2) because it limits the firm's ability to capture the higher profit from a larger group of late adopters generated from externality.

Second, comparing the two panels as shown in Figure 6, we observe that the region in which the additional familiarization is beneficial decreases as the consumers become more forward-looking (i.e., when $\delta$ is larger). That is, running promotion campaign is more attractive to the firm if the consumer base is more myopic (i.e., when $\delta$ is smaller), and less attractive if it is more forwardlooking (i.e., when $\delta$ is larger). Familiarization is beneficial because it helps accelerate adoption (shifts demand from period 2 to period 1) which enables firms to either take advantage of, or avoid unfavorable effect of, externality. When consumers are more forward looking, they are inherently disposed to delay adoption, thus making familiarization less effective.

\section{Summary and Discussion}

While existing literature focuses on the issue of social learning by examining the case when consumers are unsure about the value of a new innovative product, we consider the case where consumers are reluctant to make a purchase because they experience psychological anxiety of adoption

${ }^{5}$ When $K=0$, the two regions will be delineated by a curve resembling a horizontal line around $\beta=0.2$. Thus when $\beta$ is low, the detrimental effect of familiarization holds for all values of $\alpha$ even when $K=0$. 
associated with disrupting established routine or habit, learning the necessary steps to use the innovation effectively, or parting from an emotionally attached old technology. Such anxiety can be mitigated by the firm's effort to help consumers to become familiarized with the product and by the number of early adopters, i.e., externality. We investigated how these two effects interact and examined how they affect the firm's optimal promotion and pricing strategies.

Although pricing is an important lever to maximize profits associated with new product launches in the presence of externality, and such optimal pricing policies have been studied in the literature (Dhebar and Oren 1985, Xie and Sirbu 1995), a similarly important lever for anxiety-inducing new products is a firm's familiarization strategy, which has received relatively little attention in the externality literature. As an initial attempt to examine the role of consumers' psychological anxieties and their impact on a firm's decisions, we have developed a parsimonious modeling framework. Our equilibrium analysis reveals that, unlike the conventional wisdom for promoting new products, for anxiety-inducing innovations with externality, accelerating the speed of adoption through promotion can be detrimental to the firm.

Furthermore, our closed-form expressions offer clear insights into when and why familiarization and/or externality is beneficial and leads to some rule-of-thumb recommendations for firm's pricing and promotion strategies, as summarized in Table 3. We find that, (i) when externality is absent, price mark-down is always optimal, however, price mark-up is optimal when externality is present and is more favorable; (ii) firm should carefully devise its promotion campaign because it can be detrimental when externality is present and favorable. Overall, this paper highlights the importance of studying the interaction of the externality and familiarization effect.

Various extensions to our model are possible. Our model currently assumes that consumers discount future consumption but the firm does not (or equivalently up to a scalar multiple, that consumers discount future more heavily than the firm). If the firm discounts future more heavily than the consumers, which may be relevant in an entrepreneurial setting, the firm may always benefit from accelerated adoption. It may be interesting to understand the implication of the firm's 


\begin{tabular}{|c|c|c|}
\hline \multirow{2}{*}{ Externality } & \multicolumn{2}{|c|}{ Effectiveness of Familiarization Campaign } \\
\cline { 2 - 3 } & Less Effective (low $\alpha)$ & More Effective (high $\alpha$ ) \\
\hline \multirow{2}{*}{ Not present } & Invest in Familiarization & Don't Invest in Familiarization \\
\hline Present & Price mark down & Price mark down \\
\hline (unfavorable (high $\beta))$ & Invest in Familiarization & Don't Invest in Familiarization \\
\hline Present & Price mark up & Price mark down \\
$($ favorable $($ low $\beta))$ & Don't Invest in Familiarization & Don't Invest in Familiarization \\
\hline
\end{tabular}

Table 3 Rule-of-Thumb Recommendation for Firm's Promotion and Pricing Strategy.

discount factor on their promotion and pricing strategy. Externalities can also be negative, for example when consumers seek exclusivity or status-seeking behavior (Gao et al. 2016). As such, an interesting future work may be to examine a product launch setting that engenders negative externality. Moreover, how should firms make decisions when the anxiety-alleviating effects $\alpha$ and $\beta$ are uncertain, or how the results might change when the distribution of the anxiety level $x_{i}$ is altered (Johnson and Myatt 2006) can also be interesting future enquiries. It is our hope that this paper will stimulate researchers to further explore consumer psychological externality and its impact on firms' operational decisions and strategies. We also believe that there are numerous opportunities to examine the issue of consumer psychological externalities via behavioral experiments.

\section{Acknowledgments}

The authors gratefully acknowledge the department editor Stelios Kavadias, the senior editor, and two anonymous reviewers for their constructive and insightful feedback which helped significantly improve this paper.

\section{References}

Abrahamson, E., L. Rosenkopf. 1993. Institutional and competitive bandwagons: Using mathematical modeling as a tool to explore innovation diffusion. Academy of Management Review, 18(3), 487-517.

Bandejee, A.V. 1992. A simple model of herd behavior. Quarterly Journal of Economics, 107(3), 797-817.

Bass, F.M. 1969. A new product growth for model of consumer durables. Management Science, 15(5), 215227.

Becker, G. S. 1991. A note on restaurant pricing and other examples of social influences on price. Journal of Political Economy, 99(5), 1109-1116. 
Bensaid, B., J.P. Lesne. 1996. Dynamic monopoly pricing with network externalities. International Journal of Industrial Organization, 14(6), 837-855.

Besanko, D., W.L. Winston. 1990. Optimal pricing skimming by a monopolist facing rational consumers. Management Science, 36(5), 555-567.

Bikhchandani, S., D. Hirshleifer, I. Welch. 1998. Learning from the behavior of others: Conformity, fads, and informational cascades. The Journal of Economic Perspectives, 12(3), 151-170.

Brynjolfsson, E., C.F. Kemerer. 1996. Network externalities in microcomputer software: An econometric analysis of the spreadsheet market. Management Science, 42(12), 1627-1647.

Castano, R., M. Kacker, H. Sujan. 2008. Managing consumer uncertainty in the adoption of new products: Temporal distance and mental simulation. Journal of Marketing Research, 45(3), 320-336.

Chattergee, R., J. Eliashberg. 1990. The innovation diffusion process in a heterogeneous population: A micromodeling approach. Management Science, 36(9), 1057-1079.

Dhebar, A., S.S. Oren. 1985. Optimal dynamic pricing for expanding networks. Marketing Science, 4(4), 336-351.

Fournier, S. 1998. Consumers and their brands: Developing relationship theory in consumer research. Journal of Consumer Research, 24(4), 343-353.

Gabszewicz, J.J., F. Garcia. 2008. A note on expanding networks and monopoly pricing. Economics Letters, 98(1), 9-15.

Gao, S.Y., W.S. Lim, C.S. Tang. 2016. Entry of copycats of luxury brands. Marketing Science, 36(2), 272-289.

Gatignon, H., T.S. Robertson. 1985. A propositional inventory for new diffusion research. Journal of Consumer Research, 11(4), 849-867.

Gatignon, H., T.S. Robertson. 1989. Technology diffusion: An empirical test of competitive effects. Journal of Marketing, 53(1), 35-49.

Goering, P.A. 1985. Effects of product trial on consumer expectations, demand, and prices. Journal of Consumer Research, 12(1), 74-82.

Goldenberg, J., B. Libai, E. Muller. 2010. The chilling effects of network externalities. International Journal of Research in Marketing, 27(1), 4-15.

Heiman, A., E. Muller. 1996. Using demonstration to increase new product acceptance: Controlling demonstration time. Journal of Marketing Research, 33(4), 422-430.

Hellofs, L.L., R. Jacobson. 1999. Market share and customers' perceptions of quality: When can firms grow their way to higher versus lower quality? Journal of Marketing, 63(1), 16-25.

Hoch, S.J., G. F. Loewenstein. 1991. Time-inconsistent preferences and consumer self-control. Journal of Consumer Research, 17(4), 492-507.

Hoeffler, S. 2003. Measuring preferences for really new products. Journal of Marketing Research, 40(4), 406-420.

Johnson, J.P., D.P. Myatt. 2006. On the simple economics of advertising, marketing, and product design. American Economic Review, 96(3), 756-784.

Katz, M.L., C. Shapiro. 1985. Network externalities, competition, and compatibility. American Economic Review, 75(3), 424-440. 
Kleijnen, M., N. Lee, M. Wetzels. 2009. An exploration of consumer resistance to innovation and its antecedents. Journal of Economic Psychology, 30(3), 344-357.

Lilien, G.L., P. Kotler, K.S. Moorthy. 1992. Marketing Models, Prentice Hall, New Jersey, USA.

Moretti, E. 2011. Social learning and peer effects in consumption: Evidence from movie sales. Review of Economic Studies, 78(1), 356-393.

Oliver, R.L. 1980. A cognitive model of the antecedents and consequences of satisfaction decisions. Journal of Marketing Research, 17(4), 460-469.

Padmanabhan, V., S. Rajiv, K. Srinivasan. 1997. New products, upgrades, and new releases: A rationale for sequential product introduction. Journal of Marketing Research, 34(4), 456-472.

Papanastasiou, Y., N. Savva. 2016. Dynamic pricing in the presence of social learning and strategic consumers. Management Science, 63(4), 919-939.

Peres, R., E. Muller, V. Mahajan. 2010. Innovation diffusion and new product growth models: A critical review and research directions. International Journal of Research in Marketing, 27(22), 91-106.

Ram, S. 1989. Successful innovation using strategies to reduce consumer resistance: An empirical test. Journal of Product Innovation Management, 6(1), 20-34.

Ram, S., J.N. Sheth. 1989. Consumer resistance to innovation: The marketing problem and its solutions. Journal of Consumer Marketing, 6(2), 5-14.

Ren, H., T. Huang. 2018. Modeling customer bounded rationality in operations management: A review and research opportunities. Computers and Operations Research, 91(2018), 48-58.

Sheth, J.N. 1981. Psychology of innovation resistance: The less developed concept (LDC) in diffusion research. Research in Marketing, 4, 273-282.

Srinivasan, R., G.L. Lilien, A. Rangaswamy. 2004. First in, first out? The effects of network externalities on pioneer survival. Journal of Marketing, 68(1), 41-58.

Sun, B., J. Xie, H.H. Cao. 2004. Product strategy for innovators in markets with network effects. Marketing Science, 23(2), 243-254.

Tellis, G.J. 2010. Network effects: Do they warm or chill a budding product? International Journal of Research in Marketing, 27(1), 20-21.

Thaler, R. 1985. Mental accounting and consumer choice. Marketing Science, 4(3), 199-214.

Wang, H. 1997. Treatment of "don't-know responses" in contingent valuation surveys: A random valuation model. Journal of Environmental Economics and Management, 32(2), 219-232.

Wang, Q. Y. Chen, J. Xie. 2010. Survival in markets with network effects: product compatibility and orderof-entry effects. Journal of Marketing, 74(4), 1-14.

Xie, J., M. Sirbu. 1995. Price competition and compatibility in the presence of positive demand externalities. Management Science, 41(5), 909-926.

Yu, M., L. Debo, R. Kapuscinski. 2016. Strategic waiting for consumer-generated quality information: Dynamic pricing of new experience goods. Management Science, 62(2), 410-435. 


\section{Appendix}

Proof of Proposition 1. Using backward induction, we will (i) solve for period 2, (ii) state the condition for the rational expectation equilibrium (REE), and (iii) solve for period 1 under the REE.

(i) In period 2 , the period 1 demand $D_{1}$ (i.e., $\tau_{1}$ ) has been realized, so $\tau_{1}$ is treated as a constant. The remaining consumers in period 2 are those who did not purchase in period 1, i.e., $x_{i}>\tau_{1}$. Given the anxiety reduction $\alpha$ and price $p_{2}$, a consumer $i$ with anxiety level $x_{i}$ will purchase the product if and only if:

$$
v-\alpha x_{i}-p_{2}>0 \Leftrightarrow x_{i}<\frac{v-p_{2}}{\alpha} \triangleq \tau_{2}
$$

Because the consumer pool anxiety levels $x_{i} \in[0, v]$, the period 2 demand curve and the resulting profit function are:

$$
\begin{aligned}
& D_{2}\left(p_{2} \mid \tau_{1}\right)=\left(\min \left\{\tau_{2}, v\right\}-\tau_{1}\right) \frac{1}{v}=\min \left\{\frac{v-p_{2}}{\alpha}-\tau_{1}, v-\tau_{1}\right\} \frac{1}{v} \\
& \pi_{2}\left(p_{2} \mid \tau_{1}\right)=p_{2} \cdot \min \left\{\frac{v-p_{2}}{\alpha}-\tau_{1}, v-\tau_{1}\right\} \frac{1}{v}=\min \{\underbrace{\left(\frac{v}{\alpha}-\tau_{1}\right) p_{2}-\frac{p_{2}^{2}}{\alpha}}_{(a)}, \underbrace{\left(v-\tau_{1}\right) p_{2}}_{(b)}\} \frac{1}{v}
\end{aligned}
$$

Figure A1 Two possible shapes for the period 2 profit function $\pi_{2}\left(p_{2}\right)$.
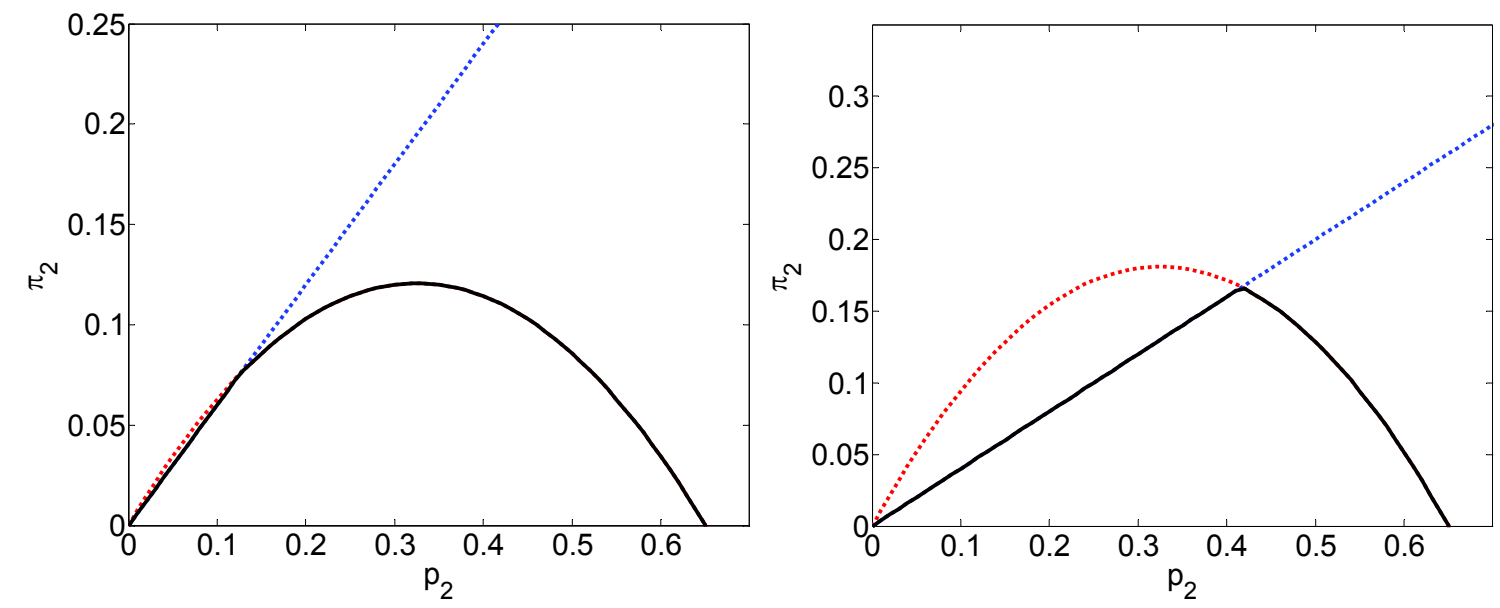

Note. The solid line represents the period 2 profit function. In the left panel, profit $\pi_{2}$ is maximized by the price that maximizes the quadratic function (a). In the right panel, profit $\pi_{2}$ is maximized by the price at which the quadratic function (a) and the linear function (b) intersect.

As illustrated in Figure A1, the profit maximizing price $p_{2}^{*}$ is either the price that maximizes the quadratic function (a), $p_{2}^{(a)} \equiv \frac{v}{2}-\frac{\alpha}{2} \tau_{1}$ (left panel), or the price at which the quadratic function (a) and the linear function (b) intersect, $p_{2}^{(b)} \equiv(1-\alpha) v$ (right panel). 
Note that if $p_{2}^{(a)}>p_{2}^{(b)}$ (left panel), then $p_{2}^{*}=p_{2}^{(a)}$ and $\pi_{2}^{*}$ equals the expression (a) evaluated at $p_{2}^{(a)}$; and if $p_{2}^{(a)} \leq p_{2}^{(b)}$, then $p_{2}^{*}=p_{2}^{(b)}$ and $\pi_{2}^{*}$ equals the expression (b) evaluated at $p_{2}=p_{2}^{(b)}$. Since $p_{2}^{(a)}>p_{2}^{(b)} \Leftrightarrow \tau_{1} \leq$ $\left(2-\frac{1}{\alpha}\right) v, p_{2}^{*}\left(\tau_{1}\right)$ and $\pi_{2}^{*}\left(\tau_{1}\right) \equiv \pi_{2}\left(p_{2}^{*}\left(\tau_{1}\right) \mid \tau_{1}\right)$ can be expressed explicitly in terms of $\tau_{1}$ as:

$$
p_{2}^{*}\left(\tau_{1}\right)=\left\{\begin{array}{l}
\frac{v}{2}-\frac{\alpha}{2} \tau_{1}, \tau_{1} \leq\left(2-\frac{1}{\alpha}\right) v, \\
(1-\alpha) v, \tau_{1}>\left(2-\frac{1}{\alpha}\right) v,
\end{array} ; \quad \pi_{2}^{*}\left(\tau_{1}\right)=\left\{\begin{array}{l}
\frac{1}{v \alpha}\left(\frac{v}{2}-\frac{\alpha}{2} \tau_{1}\right)^{2}, \tau_{1} \leq\left(2-\frac{1}{\alpha}\right) v \\
(1-\alpha)\left(v-\tau_{1}\right), \tau_{1}>\left(2-\frac{1}{\alpha}\right) v
\end{array} .\right.\right.
$$

(ii) Under the REE, a consumer with anxiety level $x_{i}$ would have purchased in period 1 if and only if $v-\alpha x_{i}-p_{1}>\delta\left(v-\alpha x_{i}-p_{2}^{*}\left(\tau_{1}\right)\right)$, where $p_{2}^{*}\left(\tau_{1}\right)$ is given by A-1). Thus, in the REE, the threshold $\tau_{1}$ is related to $p_{1}$ as follows:

$$
v-\alpha \tau_{1}-p_{1}=\delta\left(v-\alpha \tau_{1}-p_{2}^{*}\left(\tau_{1}\right)\right) \Leftrightarrow p_{1}^{*}=\left\{\begin{array}{l}
\left(1-\frac{\delta}{2}\right) v-\left(1-\frac{\delta}{2}\right) \alpha \tau_{1}, \tau_{1} \leq\left(2-\frac{1}{\alpha}\right) v \\
v(1-\delta \alpha)-(1-\delta) \alpha \tau_{1}, \tau_{1}>\left(2-\frac{1}{\alpha}\right) v
\end{array} .\right.
$$

This is illustrated in Figure A2,

Figure A2 The rational expectation equilibrium under $F$.

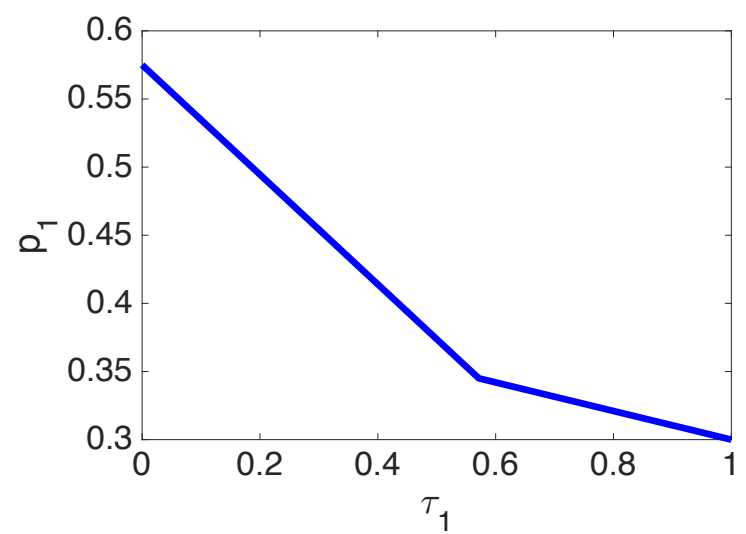

Note. In the REE, $p_{1}$ and $\tau_{1}$ are related by a piece-wise linear curve. The inflection point $\tau_{1}=\left(2-\frac{1}{\alpha}\right) v(0.58$ in this plot) depends on $\alpha$. As $\alpha$ decreases, the inflection point shifts left, and it disappears when $\alpha \leq 0.5$.

(iii) We now examine the firm's pricing decision in period 1, expressed as follows:

$$
\begin{array}{cc}
\max _{p_{1}} & p_{1} \tau_{1} \frac{1}{v}+\pi_{2}^{*}\left(\tau_{1}\right), \\
\text { s.t. } A-2 & \text { holds. }
\end{array}
$$

This is equivalent to the following maximization problem with respect to $\tau_{1}$, which consists of two subproblems based on regions of $\tau_{1}$ : (a) $\tau_{1} \leq\left(2-\frac{1}{\alpha}\right) v$ and (b) $\tau_{1}>\left(2-\frac{1}{\alpha}\right) v$.

$$
\pi^{*}=\max \left\{\max _{\tau_{1} \leq\left(2-\frac{1}{\alpha}\right) v} \pi^{(a)}\left(\tau_{1}\right) \triangleq\left[\left(1-\frac{\delta}{2}\right) v-\left(1-\frac{\delta}{2}\right) \alpha \tau_{1}\right] \tau_{1} \frac{1}{v}+\frac{1}{v \alpha}\left(\frac{v}{2}-\frac{\alpha}{2} \tau_{1}\right)^{2},\right.
$$




$$
\left.\max _{\tau_{1}>\left(2-\frac{1}{\alpha}\right) v} \pi^{(b)}\left(\tau_{1}\right) \triangleq\left[v(1-\delta \alpha)-(1-\delta) \alpha \tau_{1}\right] \tau_{1} \frac{1}{v}+(1-\alpha)\left(v-\tau_{1}\right)\right\} .
$$

Because $p_{1}^{*}\left(\tau_{1}\right)$ is continuous in $\tau_{1}$ and both $\pi^{(a)}$ and $\pi^{(b)}$ are quadratic in $\tau_{1}$, we need not consider the corner solution of $\tau_{1}=\left(2-\frac{1}{\alpha}\right) v$ separately. Taking the first-order conditions of $\pi^{(a)}$ and $\pi^{(b)}$ and performing algebraic simplifications, we have the following optimal thresholds $\tau_{1}^{(a) *}$ and $\tau_{1}^{(b) *}$ and profits $\pi^{(a) *}=\pi^{(a)}\left(\tau_{1}^{(a) *}\right)$ and $\pi^{(b) *}=\pi^{(b)}\left(\tau_{1}^{(b) *}\right)$ :

$$
\begin{aligned}
\tau_{1}^{(a) *} & =\frac{1-\delta}{\alpha(3-2 \delta)} v, & \pi^{(a) *} & =\frac{v}{4 \alpha} \cdot \frac{(2-\delta)^{2}}{3-2 \delta}-K, \\
\tau_{1}^{(b) *} & =\frac{v}{2}, & \pi^{(b) *} & =\frac{v}{4}(4-\alpha(3+\delta))-K .
\end{aligned}
$$

Note that $\pi^{(a) *}>\pi^{(b) *}$ if and only if $\alpha>\hat{\alpha} \triangleq \frac{2+\sqrt{4-(3+\delta) \frac{(2-\delta) 2}{(3-2 \delta)}}}{3+\delta}$. Thus, if $\alpha>\hat{\alpha}$, the expressions for the equilibrium prices $\left(p_{1}^{*}, p_{2}^{*}\right)$, demands $\left(D_{1}^{*}, D_{2}^{*}\right)$, and profits $\left(\pi_{1}^{*}, \pi_{2}^{*}, \pi^{*}\right)$ can be found by substituting $\tau_{1}^{(a) *}=$ $\frac{1-\delta}{\alpha(3-2 \delta)} v$ into the relevant expressions. Otherwise, they can be found by substituting $\tau_{1}^{(b) *}=\frac{v}{2}$.

Proof of Propositions 2-3. To avoid repetition, we focus on the proof of Proposition 3, which includes the proof of Proposition 2 as a special case with $\alpha=1$. Using backward induction, we will (i) solve for period 2, (ii) identify the condition for the rational expectation equilibrium (REE), and (iii) solve for period 1 under the REE.

(i) In period 2 , the period 1 demand $D_{1}$ (i.e., $\tau_{1}$ ) is realized, so $\tau_{1}$ is treated as a constant. PE, which depends on $D_{1}$, has reduced the consumer anxiety level by a factor of $\left(\beta / D_{1}\right)=\left(\beta v / \tau_{1}\right)$. Given that the familiarization effect $\alpha$ has taken effect and the period 2 price is $p_{2}$, a consumer with anxiety level $x_{i}$ will purchase in period 2 if and only if:

$$
v-\alpha\left(\frac{\beta}{D_{1}}\right) x_{i}-p_{2}>0 \Leftrightarrow x_{i}<\left(v-p_{2}\right) \frac{\tau_{1}}{\alpha \beta v} \triangleq \tau_{2} .
$$

Here, for period 2, we consider the case where $D_{1}<1\left(\tau_{1}<v\right)$. For the case $D_{1}=1$ that has no period 2 problem, which is only possible when $\alpha<1$, go to the period 1 problem in part (iii).

Because we consider a pool of consumers whose anxiety level $x_{i} \in[0, v]$, the period 2 demand curve and the resulting profit function are:

$$
\begin{aligned}
& D_{2}\left(p_{2} \mid \tau_{1}\right)=\left(\min \left\{\tau_{2}, v\right\}-\tau_{1}\right) \frac{1}{v}=\min \left\{\frac{\tau_{1}}{\alpha \beta}-\tau_{1}-\frac{\tau_{1}}{v \alpha \beta} p_{2}, v-\tau_{1}\right\} \frac{1}{v}, \\
& \pi_{2}\left(p_{2} \mid \tau_{1}\right)=p_{2} D_{2}\left(p_{2} \mid \tau_{1}\right)=\min [\underbrace{\left(\frac{1}{\alpha \beta}-1\right) \tau_{1} p_{2}-\frac{\tau_{1}}{v \alpha \beta} p_{2}^{2}}_{(a)}, \underbrace{p_{2}\left(v-\tau_{1}\right)}_{(b)}] \frac{1}{v} .
\end{aligned}
$$


As illustrated in Figure A1, the profit maximizing price $p_{2}^{*}$ is either the price that maximizes the quadratic function (a), $p_{2}^{(a)}=\frac{v(1-\alpha \beta)}{2}$ (left panel), or the price at which the quadratic function (a) and the linear function (b) intersect, $p_{2}^{(b)}=v-\frac{\alpha \beta v^{2}}{\tau_{1}}$ (right panel).

Note that if $p_{2}^{(a)}>p_{2}^{(b)}$ (left panel), then $p_{2}^{*}=p_{2}^{(a)}$ and the optimal $\pi_{2}^{*}$ equals the expression (a) evaluated at $p_{2}^{(a)}$; otherwise, $p_{2}^{*}=p_{2}^{(b)}$ and $\pi_{2}^{*}$ equals the expression (b) evaluated at $p_{2}^{(b)}$. Since $p_{2}^{(a)}>p_{2}^{(b)} \Leftrightarrow \tau_{1} \leq \frac{2 \alpha \beta v}{1+\alpha \beta}$, $p_{2}^{*}\left(\tau_{1}\right)$ and $\pi_{2}^{*}\left(\tau_{1}\right) \equiv \pi_{2}\left(p_{2}^{*}\left(\tau_{1}\right) \mid \tau_{1}\right)$ can be expressed explicitly in terms of $\tau_{1}$ as:

$$
p_{2}^{*}\left(\tau_{1}\right)=\left\{\begin{array}{ll}
\frac{v}{2}(1-\alpha \beta), \quad \tau_{1} \leq \frac{2 \alpha \beta v}{1+\alpha \beta}, \\
v\left(1-\frac{\alpha \beta v}{\tau_{1}}\right), & \tau_{1}>\frac{2 \alpha \beta v}{1+\alpha \beta} .
\end{array} \quad \pi_{2}^{*}\left(\tau_{1}\right)= \begin{cases}\frac{1}{4} \frac{(1-\alpha \beta)^{2}}{\alpha \beta} \tau_{1}, & \tau_{1} \leq \frac{2 \alpha \beta v}{1+\alpha \beta} \\
\left((1+\alpha \beta) v-\frac{\alpha \beta v^{2}}{\tau_{1}}-\tau_{1}\right), & \tau_{1}>\frac{2 \alpha \beta v}{1+\alpha \beta}\end{cases}\right.
$$

(ii) Under the REE, consumer $i$ with anxiety level $x_{i}$ will purchase in period 1 if and only if $v-\alpha x_{i}-p_{1}>$ $\delta\left(v-x_{i} \alpha \beta \frac{v}{\tau_{1}}-p_{2}^{*}\left(\tau_{1}\right)\right)$, where $p_{2}\left(\tau_{1}\right)$ is given by $\mathrm{A}-3$. Solving for $\tau$, the threshold $\tau_{1}$ and $p_{1}$ under the REE are related as follows:

$$
v-\alpha \tau_{1}-p_{1}=\delta\left(v-\tau_{1} \alpha \beta \frac{v}{\tau_{1}}-p_{2}\right) \Leftrightarrow p_{1}=\left\{\begin{array}{l}
v\left(1-\frac{\delta}{2}(1-\alpha \beta)\right)-\alpha \tau_{1}, \quad \tau_{1} \leq \frac{2 \alpha \beta v}{1+\alpha \beta} \\
v(1+\delta \alpha \beta)-\frac{\delta \alpha \beta v^{2}}{\tau_{1}}-\alpha \tau_{1}, \tau_{1}>\frac{2 \alpha \beta v}{1+\alpha \beta} .
\end{array}\right.
$$

This expression, however, is not well-defined because there are two $\tau_{1}$ at which $v\left(1-\frac{\delta}{2}(1-\alpha \beta)\right)-\alpha \tau_{1}=$ $v(1+\delta \alpha \beta)-\frac{\delta \alpha \beta v^{2}}{\tau_{1}}-\alpha \tau_{1}$, namely, $\tau_{1}=\frac{2 \alpha \beta v}{1+\alpha \beta}$ and $\tau_{1}=\frac{v \delta(1+\alpha \beta)}{2 \alpha}$. To ensure that the REE relationship between $p_{1}^{*}$ and $\tau_{1}$ is well-defined, the region $\tau_{1} \in\left[\frac{2 \alpha \beta v}{1+\alpha \beta}, \frac{v \delta(1+\alpha \beta)}{2 \alpha}\right]$ must be accounted for to be a one-to-one mapping. This leads to the following REE condition, which is illustrated in Figure A3:

$$
p_{1}= \begin{cases}v\left(1-\frac{\delta}{2}(1-\alpha \beta)\right)-\alpha \tau_{1}, & \tau_{1}<\frac{2 \alpha \beta v}{1+\alpha \beta} \\ v(1+\delta \alpha \beta)-\frac{\delta \alpha \beta v^{2}}{\tau_{1}}-\alpha \tau_{1}, & \tau_{1} \geq \frac{v \delta(1+\alpha \beta)}{2 \alpha} .\end{cases}
$$

Note the two different scenarios depending on the value of $\frac{\delta(1+\alpha \beta)}{2 \alpha}$. If $\frac{v \delta(1+\alpha \beta)}{2 \alpha}<v$ (left panel), which is always true for the E-only case $(\alpha=1)$, then the REE occurs in two disjoint ranges of $\tau_{1}, \tau_{1}<\frac{2 \alpha \beta v}{1+\alpha \beta}$ and $\tau_{1} \geq \frac{v \delta(1+\alpha \beta)}{2 \alpha}$, as in $\mathrm{A}-5$. If $\frac{v \delta(1+\alpha \beta)}{2 \alpha} \geq v$ (right panel), the REE occurs in either the continuous range of $\tau_{1}<\frac{2 \alpha \beta v}{1+\alpha \beta}$ or $\tau_{1}=1$. For this case, the REE expression $\mathrm{A}-5$ is updated to

$$
p_{1}= \begin{cases}v\left(1-\frac{\delta}{2}(1-\alpha \beta)\right)-\alpha \tau_{1}, & \tau_{1}<\frac{2 \alpha \beta v}{1+\alpha \beta} \\ v\left(1-\frac{\delta}{2}(1-\alpha \beta)-\frac{2 \alpha^{2} \beta}{1+\alpha \beta}\right), & \tau_{1}=v\end{cases}
$$

(iii) We now examine the firms pricing decision in period 1. If $\frac{\delta(1+\alpha \beta)}{2 \alpha} \leq 1$, which is always true for the E-only case (Proposition 2), we have

$$
\begin{array}{ll}
\max _{p_{1}} & p_{1} \tau_{1} \frac{1}{v}+\pi_{2}^{*}\left(\tau_{1}\right) \\
\text { s.t. } & A-5 \text { holds, }
\end{array}
$$


Figure A3 The formation of the rational expectation equilibrium under $F+E$.
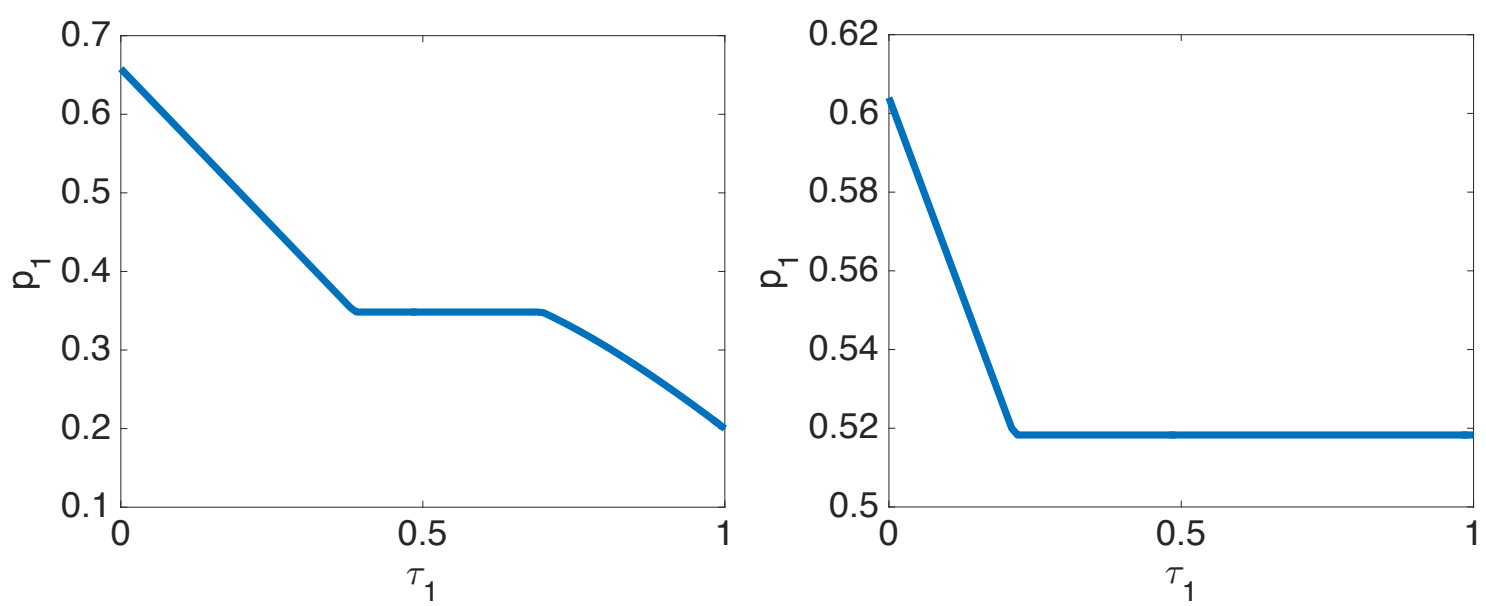

Note. In the REE, $p_{1}$ and $\tau_{1}$ are related by two disjoint curves defined by two inflection points, $\tau_{1}=\frac{2 \alpha \beta v}{1+\alpha \beta}$ and $\tau_{1}=\frac{v \delta(1+\alpha \beta)}{2 \alpha}$. If $\frac{\delta(1+\alpha \beta)}{2 \alpha}<1$ (left panel), the second inflection point is within the range $[0, v]$. If $\frac{\delta(1+\alpha \beta)}{2 \alpha}>1$ (right panel), the second inflection point is outside the range $[0, v]$. Parameters: $v=1, \delta=0.9, \beta=0.3, \alpha=0.8$ (for left panel) and $\alpha=0.4$ (for right panel).

which can be solved by maximizing over $\tau_{1}$, i.e.,

$$
\begin{aligned}
\pi^{*}=\max \left\{\max _{\tau_{1} \leq \frac{2 \alpha \beta v}{1+\alpha \beta}} \pi^{(a)} \triangleq\left[v\left(1-\frac{\delta}{2}(1-\alpha \beta)\right)-\alpha \tau_{1}\right] \tau_{1} \frac{1}{v}+\frac{1}{4} \frac{(1-\alpha \beta)^{2}}{\alpha \beta} \tau_{1},\right. \\
\left.\max _{\tau_{1}>\frac{v \delta(1+\alpha \beta)}{2 \alpha}} \pi^{(b)} \triangleq\left[v(1+\delta \alpha \beta)-\frac{\delta \alpha \beta v^{2}}{\tau_{1}}-\alpha \tau_{1}\right] \tau_{1} \frac{1}{v}+\left[(1+\alpha \beta) v-\frac{\alpha \beta v^{2}}{\tau_{1}}-\tau_{1}\right]\right\} .
\end{aligned}
$$

Otherwise, if $\frac{\delta(1+\alpha \beta)}{2 \alpha}>1$, we have

$$
\begin{gathered}
\max _{p_{1}} p_{1} \tau_{1} \frac{1}{v}+\pi_{2}^{*}\left(\tau_{1}\right), \\
\text { s.t. } A-6 \text { holds, }
\end{gathered}
$$

which can be solved by maximizing over $\tau_{1}$, i.e.,

$$
\begin{gathered}
\pi^{*}=\max \left\{\max _{\tau_{1} \leq \frac{2 \alpha \beta}{1+\alpha \beta}} \pi^{(a)} \triangleq\left[v\left(1-\frac{\delta}{2}(1-\alpha \beta)\right)-\alpha \tau_{1}\right] \tau_{1} \frac{1}{v}+\frac{1}{4} \frac{(1-\alpha \beta)^{2}}{\alpha \beta} \tau_{1},\right. \\
\left.\pi^{(c)} \triangleq v\left(1-\frac{\delta}{2}(1-\alpha \beta)-\frac{2 \alpha^{2} \beta}{1+\alpha \beta}\right)\right\} .
\end{gathered}
$$

We next solve $\pi^{(a)}$ and $\pi^{(b)}$. First, since the function $\pi^{(a)}$ is quadratic in terms of $\tau_{1}$, we can find $\tau_{1}^{(a) *}$ and $\pi^{(a) *} \equiv \pi^{(a)}\left(\tau_{1}^{(a) *}\right)$ by taking the first-order conditions. We have:

$$
\tau_{1}^{(a) *}=\frac{v}{2 \alpha}\left(1-\frac{\delta}{2}(1-\alpha \beta)\right)+\frac{v}{2 \alpha} \frac{(1-\alpha \beta)^{2}}{4 \alpha \beta}, \pi^{(a) *}=\frac{v}{4 \alpha}\left(\frac{1-\delta}{2}+\left(\frac{2 \delta+1}{4}\right) \alpha \beta+\frac{1}{4 \alpha \beta}\right)^{2} .
$$


Next, note that the function $\pi^{(b)}$ is not quadratic due to the $\tau^{-1}$ term but is nonetheless unimodal in terms of $\tau_{1}$. Again taking the first-order condition of the expression, we have:

$$
(1+\delta \alpha \beta)-2 \alpha \tau_{1} \frac{1}{v}+\frac{v^{2} \alpha \beta}{\tau_{1}^{2}}-1=0 \Leftrightarrow \tau_{1}^{3}-\frac{\delta \beta v}{2} \tau_{1}^{2}-\frac{v^{3}}{2} \beta=0 .
$$

We thus have a cubic function with a unique root, which can be found through the cubic equation. So taking into account the corner solution, we have:

$$
\begin{gathered}
\tau_{1}^{(b) *}=\max \left\{\min \left\{\frac{v \delta(1+\alpha \beta)}{2 \alpha}, v\right\}, \quad v\left\{\left[\left(\frac{\delta \beta}{6}\right)^{3}+\frac{\beta}{4}+\sqrt{\frac{\beta}{2}\left(\frac{\delta \beta}{6}\right)^{3}+\left(\frac{\beta}{4}\right)^{2}}\right]^{\frac{1}{3}}\right.\right. \\
\left.\left.+\left[\left(\frac{\delta \beta}{6}\right)^{3}+\frac{\beta}{4}-\sqrt{\frac{\beta}{2}\left(\frac{\delta \beta}{6}\right)^{3}+\left(\frac{\beta}{4}\right)^{2}}\right]^{\frac{1}{3}}+\frac{\delta \beta}{6}\right\}\right\} .
\end{gathered}
$$

Substituting the expression for thresholds $\tau_{1}^{(b) *}$, we obtain the maximizing profit $\pi^{(b) *} \equiv \pi^{(b)}\left(\tau_{1}^{(b) *}\right)$.

For the region where $\frac{\delta(1+\alpha \beta)}{2 \alpha} \leq 1$, if $\pi^{(a)}>\pi^{(b)}$, then $\pi^{*}=\pi^{(a)}$ and the optimal prices and demands follow those of problem (a); otherwise, $\pi^{*}=\pi^{(b)}$ and the optimal prices and demands follow those of problem (b). For the region where $\frac{\delta(1+\alpha \beta)}{2 \alpha}>1$, if $\pi^{(a)}>\pi^{(c)}$, then $\pi^{*}=\pi^{(a)}$ and the optimal prices and demands follow those of problem (a); otherwise $\pi^{*}=\pi^{(c)}$ and the optimal prices and demands follow those of problem (c). Comparing the closed-form expressions of $\pi^{(a)}, \pi^{(b)}$, and $\pi^{(c)}$, we can simplify the above and show that there exists an implicitly defined unique crossing point $\hat{\beta}(\alpha, \delta)$ where (a) dominates iff $\beta>\hat{\beta}(\alpha, \delta)$; (b) dominates iff $\beta<\hat{\beta}(\alpha, \delta)$ and $\alpha \geq \frac{\delta}{2-\delta \beta}$; and (c) dominates otherwise.

Proof of Corollaries 1 - 3. The results follow directly from the respective closed-form expressions of Propositions $1-3$. 